GLAUCE MARY GOMES RITTNER

\title{
TERAPIA GÊNICA CONTRA PARACOCCIDIOIDOMICOSE EXPERIMENTAL UTILIZANDO CAMUNDONGOS BALB/C E B10.A E VETORES DE EXPRESSÃO DE P10, HSP60 E IL-12
}

Tese apresentada ao Instituto de Ciências Biomédicas da Universidade de São Paulo, para obtenção do título de Doutor em Ciências (Microbiologia).

Área de concentração: Microbiologia

Orientador: Prof. Dr. Luiz Rodolpho Raja Gabaglia Travassos

\section{São Paulo}




\section{RESUMO}

RITTNER, G. M. G. Terapia gênica contra paracoccidioidomicose experimental utilizando camundongos BALB/c e B10.A e vetores de expressão de P10, HSP60 e IL-12. 2008. 196 f. Tese (Doutorado em Ciências - Microbiologia) Instituto de Ciências Biomédicas, Universidade de São Paulo, São Paulo, 2008.

A paracoccidioidomicose (PCM) é uma doença sistêmica de caráter granulomatoso, causada pelo fungo termodimórfico Paracoccidioides brasiliensis. A PCM é endêmica nas Américas do Sul e Central. Vacina de DNA é uma abordagem promissora e atual na imunoterapia. O peptídeo P10 contem um epítopo da gp43 reconhecido por linfócitos T-CD4+ e é protetor contra a PCM experimental. No presente trabalho analizamos o uso de vacinas de DNA usando vetores de expressão de P10, IL-12 e HSP60 em camundongos infectados intratraquealmente (i.t.) com $P$. brasiliensis. Esquema Profilático: camundongos BALB/c foram imunizados com pCDNA3 com sequências codificadoras de P10, HSP60 ou IL-12 e foram infectados i.t com $3 \times 10^{5}$ leveduras do isolado $\mathrm{Pb} 18$. Esquema Terapêutico: Camundongos BALB/C e B10.A foram infectados i.t. e após 30 dias foram submetidos à imunização por 4 semanas, ou 5 meses somente para B10.A, com pCDNA3 codificando P10 e/ou IL-12. Níveis de anticorpos, unidades formadoras de colônias (UFC) e produção de citocinas foram analizados. Foi observada redução significativa de UFC nos pulmões dos camundongos imunizados com vetor contendo P10/IL-12. A histopatologia dos pulmões mostrou áreas preservadas e redução de inflamação nestes animais. O nível de citocinas nos pulmões mostrou aumento de IFN-y e IL-12 caracterizando uma resposta Th1. Tratamento de animais B10.A com pP10 até 5 meses, reduziu o número de leveduras infectantes perto de esterilização.

Palavras-chave: Vacina; P. brasiliensis; Paracoccidioidomicose; P10; HSP60; IL-12. 


\begin{abstract}
RITTNER, G. M. G. Gene therapy against experimental paracoccidioidomycosis using $B A L B / C$ and B10.A mice and expression vectors encoding P10, HSP60 and IL-12. 2008. 196 f. Tese (Doutorado em Ciências - Microbiologia) - Instituto de Ciências Biomédicas, Universidade de São Paulo, São Paulo, 2008.

Paracoccidiodomycosis (PCM) is a systemic granulomatous disease caused by the thermo-dimorphic fungus Paracoccidioides brasiliensis. It is widespread in South and Central America. Gene therapy is a promising approach to Ag-specific immunotherapy. Peptide 10 contains the T-cell epitope of gp43 and is protective against experimental infection in mice. Presently, we analyzed the used of DNAbased vaccine encoding P10, IL-12 and HSP60 in mice intratracheally infected with $P$. brasiliensis. Prophylactic protocol: BALB/c mice were immunized with pCDNA3 encoding P10, HSP60 or IL-12 prior to intratracheal infection with $3 \times 10^{5}$ yeast cells of isolate $\mathrm{Pb} 18$. Therapeutic protocol: $\mathrm{BALB} / \mathrm{C}$ and B10.A mice were infected and after 30 days, they were immunized for 4 weeks, or 5 months for B10.A only, with pCDNA3 encoding P10 and/or IL-12. Antibody titers in sera, colony forming units (CFU) and cytokine production were measured. A significant reduction of CFU in the lungs of mice immunized with plasmid encoding P10/IL-12 was observed. The lung histopathology confirmed the results showing preserved areas and reduction of inflammation in vaccinated animals. The cytokine levels in lungs showed enhanced levels of IFN-y and IL-12 characterizing a Th1 response. Further treatment of B10.A mice up to 5 months with pP10 reduced the number of infective yeasts close to sterilization.
\end{abstract}

Keywords: Vaccine; P. brasiliensis; Paracoccidioidomycosis; P10; HSP60; IL-12. 


\section{INTRODUÇÃO}

\subsection{Paracoccidioidomicose e seu agente etiológico}

A paracoccidioidomicose (PCM) é uma micose profunda de caráter granulomatoso crônico, que compromete especialmente o tecido pulmonar, o sistema linfático, o tecido mucocutâneo e por extensão qualquer outro órgão. Seu agente etiológico, Paracoccidioides brasiliensis é um fungo dimórfico, que se apresenta sob a forma de levedura quando cultivado a $37^{\circ} \mathrm{C}$ ou em vida parasitária e sob a forma de micélio, quando cultivado à temperatura ambiente (RESTREPO et al., 1969; RESTREPO, 1978).

A fase leveduriforme caracteriza-se por células esféricas ou ovais de 5-25 $\mu \mathrm{m}$ de diâmetro, com paredes bem definidas, refringentes, aparentemente duplas, que podem apresentar brotamento multipolar característico. A fase filamentosa apresenta hifas delgadas, e como formas reprodutivas aleurioconídias, artroconídias, artroaleurioconídias e clamidosporos intercalares, dependendo das condições de cultivo empregadas. Entretanto, nenhuma das estruturas reprodutivas da fase filamentosa revelou-se especialmente útil como critério para a sua identificação (LACAZ, 1994).

A doença foi inicialmente descrita por Lutz em 1908. Após esta data, iniciouse uma fase de estudos das principais características do agente infectante, como diferenças morfológicas e temperatura de cultivo. Splendore, em 1912 sugeriu a classificação do agente no gênero Zymonema (LACAZ, 2002), recebendo assim a denominação de Zymonema brasiliense. A doença passou, então, a ser denominada de "blastomicose brasileira" e, logo a seguir, "blastomicose sul-americana", já que foram relatados casos isolados em outros países da América do Sul. Em 1930, Floriano Paulo de Almeida oficializou o gênero Paracoccidiodes e revalidou o nome da espécie brasiliensis descrita por Splendore, em 1912 (ALMEIDA, 1930). Taxonomicamente, o fungo $P$. brasiliensis era classificado, até o momento, como: Reino Fungi, Filo Eumycota, Subdivisão Deuteromycotina, Classe Hyphomycetes, 
Ordem Moniliales, Família Moniliaceae Gênero Paracoccidioides e Espécie brasiliensis (LACAZ, 2002). Contudo, outra classificação foi proposta, pois estudos filogenéticos empregando ferramentas moleculares posicionaram o agente etiológico da PCM, junto aos demais fungos dimórficos (Coccidioides posadasii, C. immitis, Blastomyces dermatitidis e Histoplasma capsulatum), como pertencentes á seguinte categoria taxonômica: Reino Fungi, Filo Ascomycota, Classe Pleomycetes, Ordem Onigenales, Família Onygenaceae, Gênero Paracoccidioides e Espécie brasiliensis, sendo denominado então de Paracoccidioides brasiliensis (SAN-BLAS, 2002).

$\mathrm{Na}$ tentativa de descobrir o habitat natural do fungo, Negroni (1966) e Albornoz (1971) isolaram o fungo $P$. brasiliensis do solo. A partir de então, estudos a respeito do nicho deste fungo começaram a ser realizados. Silva-Vergara et al. (1998) isolaram o fungo a partir de solo de regiões com plantação de café no Estado de Minas Gerais, sugerindo que esse é um dos habitats do fungo $P$. brasiliensis, reafirmando, assim, a hipótese da PCM ser comum nas áreas agrícolas. Naiff et al. (1986) isolaram o fungo do tatu (Dasypus novemcinctus) no Estado do Pará, em Botucatu, o fungo também foi isolado neste animal (BAGAGLI et al., 1998). SilvaVergara et al. (2000) mostrou a frequente ocorrência da PCM nesse mamífero e seu papel como possível hospedeiro silvestre no ciclo epidemiológico do fungo $P$. brasiliensis. Outros estudos descrevem o isolamento do fungo de animais infectados como os cachorros (FARIAS et al., 2005), espécies de macacos (JOHNSON e LANG, 1996) e em pinguins (GARCIA et al., 1993; GEZUELE, 1989), sendo que provavelmente esses animais foram infectados a partir de solos contaminados com 0 fungo (FRANCO et al., 2000).

Borelli (1972) criou o termo "reservarea" para indicar o habitat natural do $P$. brasiliensis, ou seja, o local onde o indivíduo pode infectar-se com o fungo. Essas regiões normalmente estão sob a influência de um clima tropical, apresentando verão quente e úmido, com inverno frio e seco. As "reservareas" ficam frequentemente em lugares elevados, próximos a rios e a outros cursos de água. $A$ mais importante condição climática para o crescimento desse microrganismo parece ser a temperatura, que varia entre $18{ }^{\circ} \mathrm{C}$ e $24{ }^{\circ} \mathrm{C}$ (RESTREPO-MORENO, 1994). Com base no diagnóstico da PCM em residentes locais, 14 "reservareas" foram 
identificadas no Brasil, as quais estão localizadas a margem de rios, colinas com altitudes entre 52 e 950 metros acima do nível do mar e em áreas com vegetação estendendo-se desde florestas tropicais até savanas (WANKE e LONDERO, 1994).

Há evidências de que o fungo penetre no hospedeiro pelas vias aéreas superiores através da inalação de propágulos da sua fase filamentosa, dando origem a um complexo primário pulmonar, podendo, em condições de imunosupressão ocorrer disseminação hematogênica e/ou linfática para outros órgãos (FRANCO, 1986). No hospedeiro imunocompetente este foco inicial desaparece ou pode permanecer quiescente como infecção latente. Se o equilíbrio entre o hospedeiro e o parasita for rompido, poderá ocorrer a doença (MONTENEGRO, 1986).

A doença geralmente apresenta-se sob duas formas: aguda ou subaguda (tipo juvenil) e forma crônica (tipo adulto). A primeira delas é responsável por 3 a $4 \%$ dos casos e caracteriza-se por rápida disseminação para o sistema retículoendotelial. A forma crônica pode ser subdividida em unifocal e multifocal. A doença progride lentamente e pode levar de meses a anos para se manifestar e as manifestações pulmonares estão presentes em até 90\% dos casos (BRUMMER et al., 1993). Na unifocal, em $25 \%$ dos casos, os pulmões e, raramente outros locais são os únicos órgãos envolvidos (LONDERO e RAMOS, 1990). Na forma multifocal, além dos pulmões, os principais sítios envolvidos são mucosa oral e pele, linfonodos e glândulas adrenais e, em menor grau de frequência, sistema nervoso central, ossos, órgãos genitais e vasos sanguíneos.

A PCM é endêmica em países da América Latina, desde o México $\left(23^{\circ} \mathrm{N}\right)$ até a Argentina, com prevalência em países da América do Sul (RESTREPO et al., 2001). No território brasileiro, a incidência desta micose é maior nas regiões Sul, Sudeste e Centro-Oeste (WANKE et al., 1994). Em relação à situação atual da PCM, existe uma carência de dados na América Latina, mas em um estudo realizado por McEwen et al. (1987) sugeriu que cerca de 10 milhões de pessoas que vivem em regiões endêmicas podem ter entrado em contato com o fungo P.brasiliensis onde cerca de $2 \%$ poderão desenvolver a doença. Estudos epidemiológicos conduzidos 
por Coutinho et al. (2002) apresentaram dados referentes à mortalidade provocada pela PCM em regiões brasileiras entre os anos de 1980 e 1995. As maiores taxas de mortalidade por ano ocorreram na região Sudeste e Sul, especificamente em São Paulo (59,38\%), Paraná (28,9\%), Minas Gerais (24,9\%), e Rio Grande do Sul $(17,50 \%)$. Foram observados também dados referentes às outras regiões como Norte, Nordeste e Centro-Oeste, nas quais os estados mais afetados foram Rondônia (3,19\%), Pará $(3,13 \%)$, Bahia (3,69\%), Maranhão (1,38\%), Mato Grosso do Sul $(7,19 \%)$ e Goiás $(6,19 \%)$. A taxa anual de mortalidade detectada foi de 1,45/milhão de habitantes. A incidência e a mortalidade por PCM no Estado de Rondônia, por exemplo, estão entre as maiores do Brasil, com índice de mortalidade que variam de 3 a 4,39 para cada 1.000.000 de habitantes. Dados recentes em relação à doença no Brasil (comunicação pessoal, Dra. Marli Prado Bueno), mostram que entre os anos de 1996 - 2004 ocorreram 915 óbitos no agrupamento da PCM, sendo 313 óbitos (33,11\%) por PCM pulmonar, 49 por PCM disseminada (5,36\%), 38 por outras formas de $\operatorname{PCM}(4,15 \%)$ e $525(57,38 \%)$ por PCM não especificada.

Acreditava-se que a PCM fosse restrita às pessoas vinculadas a zona rural. Entretanto alguns pesquisadores relataram a presença da doença em trabalhadores da indústria, comércio e em crianças de áreas urbanas (GREER et al., 1977; EMANUEL et al., 1983; BITTENCOURT et al., 1986). A presença da PCM em áreas urbanas pode ser explicada pela migração de indivíduos infectados que adoecem nos grandes centros onde são diagnosticados. Em um levantamento realizado por Forjaz em 1989, foi sugerido que o fluxo migratório de outros Estados para a grande São Paulo, até aquela data foi de $67,7 \%$ para um total de 130 pacientes estudados em um inquérito epidemiológico. Tomando como período mínimo um ano de permanência, $80,8 \%$ dos pacientes tinham desempenhado atividades na lavoura e somente $18,5 \%$ permaneciam em trabalhos rurais ao surgirem os sintomas. Somente dois indivíduos não tiveram contato anterior com o meio rural.

Os casos relatados nos EUA, África, Europa e Ásia são conhecidos como doença de importação, devido ao fato dos pacientes terem residido em regiões endêmicas em época anterior à manifestação clínica da micose (FERGUSON e 
UPTON, 1974; FOUNTAIN e SUTHIFF, 1969; CHICAMORI et al., 1984; AJELLO e POLINELLI, 1985).

Deve-se salientar que a maior parte da população, mesmo em áreas endêmicas, é resistente à doença em sua forma manifesta, onde, apesar de estabelecido o contato com o fungo e o consequente desenvolvimento de reações positivas de hipersensibilidade de tipo tardio (HTT), a maioria dos indivíduos não desenvolve a doença (FAVA-NETTO, 1961; RESTREPO, 1985; BRUMMER et al., 1993; SOUZA et al., 2000; SEMIGHINI et al., 2002).

A PCM raramente é observada em crianças e jovens, sendo mais incidente em homens com idade entre 30 e 50 anos. A mulher está mais protegida da doença, devido à presença de estrógenos endógenos que atuam através de proteínas ligantes no citosol dos fungos, inibindo a transformação de micélio em levedura (STOVER et al., 1986). Muchmore et al. (1974) verificaram que o hormônio feminino 17- $\beta$-estradiol $\left(E_{2}\right)$, em condições fisiológicas, inibia o crescimento das células leveduriformes. Foi demonstrado que o tratamento de culturas de $P$. brasiliensis com $\mathrm{E}_{2}$ alterava a expressão de proteínas durante a fase de transição micélio-levedura (CLEMONS et al., 1989). $\mathrm{O} \mathrm{E}_{2}$ pode, portanto, através desses mecanismos interferir na patogenicidade do $P$. brasiliensis.

\subsection{Paracoccidioidomicose humana}

Conídios produzidos por micélios saprófitas no meio ambiente são responsáveis pela propagação da doença e, quando são inalados, instalam-se nos pulmões, transformando-se em leveduras (FRANCO et al., 1989; McEWEN et al., 1987). A PCM começa como uma discreta e simples pneumonia assintomática que se dissemina para superfícies mucocutâneas, trato gastro intestinal, linfonodos e outros órgãos (LONDERO et al., 1972; RESTREPO et al., 1970a, 1973).

A PCM humana, em sua etiopatologia, assemelha-se muito à coccidioidomicose e a blastomicose Norte Americana. A interação de fatores 
intrínsecos ao hospedeiro, como estado nutricional, sexo, idade, genética, integridade do sistema imunológico e fatores relacionados ao próprio fungo determinam a relação entre parasita e hospedeiro, que será estabelecida após a penetração do fungo no organismo (FAVA-NETTO et al., 1965; LACAZ, 1977; FRANCO e MONTENEGRO, 1982).

$\mathrm{Na}$ doença humana tem-se registrado a relação entre antígenos de histocompatibilidade, HLA, e incidência da doença. O HLA é um componente fundamental do sistema imune, que exerce um papel importante no processo de apresentação de peptídeos antigênicos aos linfócitos $T$, resultando ou não em uma resposta imunológica eficiente. Devido ao grande polimorfismo do HLA na população, a resposta imunológica contra determinados patógenos poderá variar entre os indivíduos que expressam HLAs distintos.

Restrepo et al. (1983) na Colômbia analisaram a frequência de HLA em pacientes com PCM e indivíduos normais. Os autores observaram que somente dois HLAs (A9 e B13) aumentaram significativamente nos pacientes, sendo que o antígeno A9 prevaleceu nos indivíduos com a forma progressiva da doença. Esses resultados sugeriram que o HLA-A9 poderia estar envolvido na susceptibilidade à doença. No Brasil, Goldani et al. (1991) relataram o aumento na frequência de haplótipos HLA-B40-Cw1 e HLA-A2-B40 nos pacientes com PCM, sugerindo possível interação entre estes antígenos. Rebellato (1996) estudou pacientes com PCM crônica, e determinou a frequência de antígenos HLA classe I e classe II, e Dias et al. (2000) analisaram somente HLA classe I em pacientes com a forma crônica da PCM. Esses autores não observaram quaisquer relações entre HLA e doença.

A PCM tem múltiplas manifestações, e duas formas clínicas progressivas são reconhecidas: forma aguda ou subaguda (tipo juvenil) e a forma crônica (tipo adulto); entretanto, ambas as formas clínicas e o curso da doença sofrem variações de paciente para paciente (FRANCO, 1986; FRANCO, 1994 e 1989; LACAZ et al., 1959). As formas agudas e subagudas estão relacionadas com extensas sequelas, 
associada às infecções sistêmicas e uma resposta imune celular deficiente. A PCM juvenil acomete adultos com menos de 30 anos e crianças de ambos os sexos, sendo responsável por $3 \%$ a $5 \%$ dos casos. A forma juvenil da PCM se desenvolve mais rapidamente, de algumas semanas a meses, sendo mais severa, levando a significante taxa de mortalidade, devido principalmente à hipertrofia dos órgãos do sistema retículo endotelial (BORGES-WALMSLEY et al., 2002).

A PCM adulta é a forma mais frequente e normalmente evolui a partir de focos quiescentes do fungo após um período indeterminado de latência. A forma crônica ou adulta da PCM abrange cerca de $90 \%$ dos casos, afetando principalmente homens adultos acima de 35 anos. A doença avança lentamente podendo levar meses ou anos para se desenvolver totalmente, afeta primariamente os pulmões (forma unifocal), podendo eventualmente causar lesões mucocutâneas com disseminação ou não para outros órgãos (forma multifocal) e tecidos causando lesões secundárias em mucosas, pele, linfonodos e glândulas adrenais. (BORGESWALMSLEY et al., 2002).

A doença no homem pode se desenvolver logo após a infecção ou anos depois, pois o fungo $P$. brasiliensis tem a capacidade de permanecer quiescente no pulmão por um período de tempo indeterminado (RESTREPO et al., 1981). Quando a doença se desenvolve pode ficar contida nos pulmões ou disseminar-se para outros órgãos ou sistemas através da via hematogênica e/ou linfática, causando lesões secundárias (FRANCO, 1986). O estabelecimento da doença, sua disseminação e gravidade dependem, de um lado, de fatores ligados ao fungo, como virulência e composição antigênica, e de outro, de fatores ligados à resposta imune do hospedeiro. Assim, nos pacientes com PCM, observa-se que formas graves da doença são acompanhadas pela perda gradual de respostas imunes celulares específicas e por altos títulos de anticorpos, já formas mais brandas, tendendo a cura, são concomitantes a respostas celulares preservadas e baixos níveis de anticorpos específicos (FRANCO et al., 1989; FRANCO e MONTENEGRO, 1982). 


\subsection{Paracoccidioidomicose experimental}

Vários autores têm relatado a utilização de animais como modelos experimentais para o estudo da PCM. As linhagens de camundongos foram classificadas dentro de quatro grupos relacionados à susceptibilidade à infecção pelo $P$. brasiliensis: grupo muito resistente (DBA/2, A/J e A/Sn); grupo resistente $(\mathrm{C} 3 \mathrm{H} / \mathrm{He})$; grupo intermediário $(\mathrm{C} 3 \mathrm{H} / \mathrm{HeB}, \mathrm{CBA}, \mathrm{C} 57 \mathrm{Bl} / 10$ e $\mathrm{BALB} / \mathrm{c})$ e grupo muito sensível (B10.D2/nSn, B10.A e B10.D2/oSn) (CALICH et al., 1985). Neste mesmo trabalho, foi observado que as fêmeas de camundongos BALB/c e B10D2/nSn foram significativamente mais resistentes que os machos. Todos os estudos foram baseados no tempo de sobrevivência dos camundongos infectados por via intraperitoneal com $\mathrm{Pb} 18$, isolado virulento de $P$. brasiliensis.

Na PCM experimental, camundongos resistentes e susceptíveis à infecção intraperitoneal com $\mathrm{O}$ isolado virulento $(\mathrm{Pb} 18)$ de $P$. brasiliensis reproduzem, respectivamente, as formas crônicas brandas e graves da doença (CALICH et al, 1985). Camundongos susceptíveis, da linhagem B10.A, tendem à resposta imune humoral, com comprometimento da imunidade celular; tais animais apresentam secreção preferencial de anticorpos de isotipos $\lg A$ e $\lg _{2 b}$, baixa produção de Interferon-gama (IFN- $\gamma$ ), secreção precoce de altos níveis de interleucina-5 (IL-5) e IL-10, eosinofilia, desenvolvimento progressivo de anergia a antígenos específicos do fungo $P$. brasiliensis em reações de hipersensibilidade do tipo tardio (HTT) e ativação reduzida e efêmera de macrófagos e neutrófilos polimorfonucleares, o que leva ao desenvolvimento de uma doença progressiva. Por outro lado, camundongos resistentes, da linhagem $\mathrm{A} / \mathrm{J}$, tendem à resposta imune celular, em detrimento da imunidade humoral; estes animais apresentam controle da multiplicação fúngica em diversos órgãos e tecidos, secreção preferencial de anticorpos do isotipo $\lg G_{2 a}$, produção contínua de IFN- $\gamma$ e IL-2, manutenção de reações de HTT a antígenos específicos do fungo $P$. brasiliensis e ativação continuada de macrófagos e neutrófilos, o que conduz à resolução do processo infeccioso. Em relação à PCM murina, salienta-se que não há o desenvolvimento de perfis Th1/Th2 inteiramente polarizados, embora a secreção de IL-2 e IFN- $\gamma$ sejam consideradas fundamentais para o desenvolvimento de proteção, e a predominância de IL-10 e fator de 
crescimento tumoral beta (TGF- $\beta$ ) esteja ligado à suscetibilidade à infecção. É ainda importante notar que camundongos resistentes apresentam ativação equilibrada e progressiva de linfócitos T CD4+, nos suscetíveis, esta ativação é bem mais intensa e precoce (CALICH e KASHINO, 1998). Outro resultado importante foi relatado por Arruda et al. (2004) em camundongos, que demonstraram o duplo papel da IL-4 na PCM, sendo que esta citocina poderá induzir proteção ou exacerbação da doença dependendo do padrão genético do hospedeiro. Em camundongos B10.A depletados para IL-4, surpreendentemente houve exacerbação da infecção pulmonar, embora somente pequenas alterações no padrão de imunidade celular e humoral tenham sido detectados. Em contraste os camundongos C57BL/6 depletados para IL-4 apresentaram quadros com menor gravidade quando comparados aos camundongos não depletados, sendo este fato associado à produção reduzida de citocinas Th2 e a níveis elevados de citocinas próinflamatórias. Esses dados demonstram que IL-4 deva exercer também funções importantes no controle da infecção fúngica, e não somente contrapondo as ações das citocinas da resposta Th1.

Em $P$. brasiliensis, a produção de IFN- $\gamma$ e indução de imunidade celular é de crítica importância para a defesa do hospedeiro. Arruda et al. (2002), estudaram o efeito da administração de IL-12 exógena em modelo murino susceptível à inflamação pulmonar. Os resultados obtidos mostraram uma menor disseminação da doença o que foi confirmado por um decréscimo na presença de fungos em fígado e baço. A administração de IL-12 não afetou o crescimento do fungo nos pulmões, mas provocou inflamação. Houve aumento da produção de IFN- $\gamma$ na primeira semana após a administração de IL-12. Após este período, o nível de IFN- $\gamma$ decresceu assim como os níveis de lgG1 e lgG3 após 8 semanas de infecção. Os resultados mostraram que a administração de IL-12 torna a infecção por $P$. brasiliensis menos severa, mas por ter produzido alta resposta inflamatória nos pulmões, esta administração, pelo menos nas condições utilizadas (concentração e outros parâmentros), não seria utilizada como ferramenta terapêutica. 


\subsection{Moléculas de interesse e antígenos produzidos por Paracoccidioides brasiliensis}

P. brasiliensis expressa numerosas substâncias (polissacarídeos, lipídeos, glicoproteínas) que reúnem condições físico-químicas e biológicas necessárias para atuarem como antígenos. Extratos antigênicos do fungo podem ser preparados por diferentes métodos, tais como filtrado bruto de cultura, tanto da fase leveduriforme como da micelial, extratos obtidos por tratamento de filtrado de cultura com álcool etílico, antígenos hidrossolúveis de natureza polissacarídica e antígenos somáticos obtidos por rompimento das células por processos físicos.

O processo de transição da forma filamentosa para a de levedura resulta em uma série de alterações celulares, entre as quais a da estrutura da parede é a mais conhecida. A parede celular do fungo $P$. brasiliensis é composta predominantemente de polissacarídeos do tipo quitinas e glucanas, que ocupam aproximadamente $80 \%$ do seu peso seco.

Os componentes das paredes celulares de $P$. brasiliensis de ambas as formas foram fracionados de acordo com sua solubilidade em álcali. Três frações foram caracterizadas: Fração 1, álcali insolúvel, contendo $\beta$-glucana; fração 2 , álcali solúvel e ácido insolúvel, constituída de a-glucanas; fração 3, álcali solúvel e precipitável com ácido, contendo galactomananas. A proporção de quitina na fase de leveduras era superior àquela da fase filamentosa e 95\% das glucanas presentes nessa fase eram solúveis em álcali, apresentando estrutura de $\alpha-1,3$ glucanas. Apenas $5 \%$ das glucanas de leveduras eram insolúveis em álcali com a estrutura de $\beta-1,3$ glucanas. O conteúdo de proteínas era maior na fase filamentosa. Nessa fase, $\beta-1,3$ glucanas (35-40\%) foram identificadas, pela ação de $\beta-1,3$ glucanase e por hidrólise ácida parcial. As glucanas solúveis (60-65\%) da forma filamentosa eram constituídas de uma mistura de $\alpha$ e $\beta$ glucanas. As $\alpha$ e $\beta$ glucanas formam estruturas fibrilares $e$ determinam, conjuntamente com quitina e proteínas da parede, a forma do fungo (SAN-BLAS, et al.,1976; SAN-BLAS e SAN-BLAS, 1977). 
A virulência de $P$. brasiliensis tem sido associada à $\alpha-1,3$ glucana contida na parede da célula leveduriforme do fungo (MORAES e SCHAFFER, 2002). San-Blas et al. (1984) demonstraram alteração na síntese de $\alpha-1,3$ glucana quando amostras passaram por repiques sucessivos (in vitro), ocasionando a perda ou a atenuação da sua virulência. Os mesmos autores verificaram, entretanto, que a adição de soro fetal bovino à cultura induz a produção desse polissacarídeo, com conseqüente reativação da virulência. Trabalhos realizados com modelo experimental murino observaram que as amostras pouco virulentas de $P$. brasiliensis apresentaram quantidades de $\alpha-1,3$ glucana semelhantes às de duas outras amostras virulentas, sugerindo a existência de outros fatores envolvidos na patogenicidade do fungo (ZACHARIAS et al., 1986).

Estudos indicaram que o $P$. brasiliensis produz melanina, um fator importante relacionado com a virulência de vários outros patógenos (JACOBSON e TINNELL, 1993; TORRES-GUERRERO e EDMAN 1994). É um polímero multifuncional encontrado em diversas espécies, que incluem representantes de todos os reinos (HILL, 1992). As melaninas fúngicas são pigmentos de cor marrom-escura ou preta, de alto peso molecular, sintetizados por polimerização oxidativa ou complexos fenólicos. Esses polímeros estão presentes na parede celular ou em toda a célula fúngica (WHEELER e BELL, 1987).

Na PCM, Gomez et al. (2001) demonstraram que o fungo $P$. brasiliensis é capaz de sintetizar melanina in vitro e durante a infecção. $P$. brasiliensis, na sua forma de levedura, cultivado em meio líquido simples suplementado com L-Dopa, produz um pigmento escuro estruturalmente semelhante àquele que havia sido isolado da melanização de C. neoformans (CASADEVALL,1995). De forma semelhante, a fase leveduriforme cultivada com L-Dopa foi analisada por espectroscopia-ESR (Ressonância da Rotação de Elétrons), mostrando um espectro quase idêntico àquele produzido pela melanina do C. neoformans (WANG et al., 1995). Conídios e células leveduriformes do fungo, cultivadas em meio contendo L-DOPA foram reativas com anticorpos monoclonais que reconhecem a melanina. Através de camundongos infectados com conídios de P. brasiliensis, 
foram recuperados resíduos escuros reativos com anticorpos monoclonais contra melanina (NOSANCHUK et al., 1999).

A adesão e invasão das células do hospedeiro são passos essenciais que envolvem a infecção e disseminação de patógenos. Além disso, esses patógenos utilizam de moléculas presentes em sua superfície para se ligarem a componentes da matriz extracelular e estabelecer a infecção. Barbosa et al. (2006) caracterizaram a proteína glliceraldeído-3-fosfato desidrogenase (GAPDH) do fungo $P$. brasiliensis como uma adesina, que pode estar relacionada com a adesão e invasão do fungo. Através de ensaios de Western blotting e microscopia de transmissão eletrônica a GAPDH foi detectada no citoplasma e na parede da célula da levedura. A proteína recombinante $\mathrm{GPDH}$, foi encontrada ligada na fibronectina, laminina e colágeno do tipo I. O tratamento in vitro de células leveduriformes do fungo $P$. brasiliensis com anticorpos policlonais anti-GPDH e a incubação da proteína recombinante com pneumócitos levou a inibição da aderência e internalização do fungo em culturas de células.

A atividade de uma proteinase exocelular, a serino-tiol proteinase presente na fase de levedura do fungo $P$. brasliensis foi caracterizada por Puccia et al. (1998). A proteinase do fungo foi capaz de clivar, em experimentos in vitro, em $\mathrm{pH} 7,4$ proteínas associadas com a membrana basal de humanos, como a laminina, fibronectina, colágeno do tipo IV e proteoglicanas. Sendo assim, a serino-tiol proteinase foi capaz de interferir na adesão e disseminação do fungo, podendo ser considerada um fator de virulência.

O diagnóstico da PCM pode ser feito por observação direta do fungo em sua fase leveduriforme nas secreções biológicas, por biópsia, e também, por seu isolamento em cultura. Entretanto, quando estes procedimentos não são possíveis, a deteç̧ão de anticorpos contra antígenos do fungo é muito útil para a elucidação do diagnóstico, principalmente através da técnica de imunodifusão (RESTREPO e MONCADA, 1974; CAMARGO et al., 1988). 
A primeira prova imunodiagnóstica para a PCM surgiu em 1916, quando Moses (1916) descreveu a reação de fixação de complemento (RFC). Em 1955, Fava Netto padronizou a RFC na PCM, utilizando como antígeno, uma mistura antigênica rica em pollissacarídeo de $P$. brasiliensis, encontrando sensibilidade de $90 \%$.

Ferri (1961) verificou a presença de anticorpos precipitantes em pacientes com PCM, aplicando a técnica de precipitação em gel de agarose, e utilizando como antígeno o sobrenadante de lisado de leveduras de $P$. brasiliensis. O uso rotineiro desta técnica foi introduzido por Restrepo (1966), que observou sensibilidade de $90 \%$.

Trabalhando com antígenos de filtrado de cultura das fases micelial e leveduriforme, e através da reação de imunoeletroforese Restrepo e Drouhet (1970) verificaram que o antígeno de filtrado de levedura apresentava cinco frações classificadas como $A, B, C, D$ e $E$, sendo que a fração $A$ esteve presente em todos os soros de pacientes com PCM.

Yarzábal (1976) realizou a análise imunoeletroforética de um extrato antigênico misto (celular e metabólico) de $P$. brasiliensis, empregando soros de pacientes com PCM. Todos os arcos observados somaram vinte sistemas de precipitação que foram caracterizados por letras sendo que, o arco $E$ foi obtido em todos os soros reativos. A análise em separado dos antígenos celulares e metabólicos demonstrou que as frações que geravam o arco $E$ encontravam-se no extrato metabólico. Não houve formação do arco $\mathrm{E}$ com soros heterólogos, desta forma, o arco E foi considerado específico da PCM.

Em 1978, Conti-Dias et al. realizaram uma análise comparativa entre imunoeletroforese e imunodifusão para diagnóstico da PCM. Os antígenos utilizados constituiram-se em filtrados micelial e leveduriforme preparados segundo Negroni (1968), e o filtrado leveduriforme preparado segundo Restrepo (1967). Os resultados da imunoeletroforese revelaram cinco arcos semelhantes para os três antígenos, 
sendo que o arco 1, de posição catódica foi nitidamente observado em todos os soros testados.

Todos os resultados obtidos com os trabalhos descritos levaram a uma correlação entre o arco 1 de Conti-Dias (1978), o arco A de Restrepo e Douhet (1970), também caracterizado como antígeno 1 ou banda 1 (RESTREPO e MONCADA, 1974) e o arco E de Yarzábal (1971). Em 1984, Blumer et al. descreveram a obtenção de um antígeno de filtrado micelial, rico em fração $E$ ou banda 1 e o testaram em imunodifusão, observando sensibilidade de $93 \%$ e especificidade de $100 \%$.

Em 1986, Puccia et al. identificaram uma glicoproteína de 43000 Da (gp43) a partir de sobrenadante de cultura da fase leveduriforme de $P$. brasiliensis. Esta glicoproteína foi purificada por gel filtração em coluna cromatográfica e por cromatografia de afinidade. A gp43 reagiu com soros de pacientes com PCM e com soro de coelho hiperimune anti-fração E (PUCCIA e TRAVASSOS, 1991a). A natureza do antígeno $\mathrm{E}$ foi determinada demonstrando-se ser este uma glicoproteína de $43000 \mathrm{Da}$.

Comparações da gp43 nativa e sua forma desglicosilada (Puccia et al., 1991b) através de estudos imunoquímicos, mostram que os principais epitopos reconhecidos por soros de pacientes são de natureza peptídica. Esses epitopos geram reações específicas quando a modalidade de reação sorológica se faz em fase líquida e, portanto mantendo a configuração da glicoproteina. Já as reações cruzadas que podem ocorrer devem-se principalmente a epítopos constituídos de carboidratos com resíduos de galactofuranose, presentes em baixa concentração na gp43 mas sendo abundantes em um polímero de alto peso molecular que pode contaminar as preparações de gp43. Estes epítopos estão mais expostos em ensaios de ELISA em substrato plástico. 
Camargo et al. (1991), estudaram a curva de crescimento de $P$. brasiliensis visando o estudo da secreção/excreção de gp43 em meio de cultura. Verificaram que durante o crescimento exponencial (2 a 7 dias), a liberação extracelular de gp43 era alta e depois decrescia com o envelhecimento da cultura, sendo praticamente indetectável a partir de 30 dias. A partir desta observação padronizou-se uma preparação antigênica bruta rica em gp43, através de cultura de células leveduriformes do fungo em meio líquido, por 7 dias, mantidas sob agitação constante a $37^{\circ} \mathrm{C}$. Este antígeno tornou-se referência internacional e tem sido utilizado com sucesso no diagnóstico da PCM, através do uso da técnica de imunodifusão.

A gp43 é importante na virulência do fungo, pois é uma molécula ligante de laminina, colaborando na adesão do fungo à célula hospedeira (VICENTINI et al., 1994). Por outro lado, verificou-se que $P$. brasiliensis utiliza a gp43 no processo de fagocitose, através de receptor manose-fucose em macrófagos (ALMEIDA et al., 1998). Essa ligação se deve ao padrão de glicosilação N-ligada da gp43 envolvendo uma cadeia "high-mannose" (ALMEIDA et al., 1996).

Esta glicoproteína apresenta-se através de 4 perfis de isoformas, classificadas como A, B, C e D, os quais diferem quanto aos seus pontos isoelétricos (pls), sendo o perfil A caracterizado através dos pls 6,0;6,3;6,6 e 7,0, perfil $B$, pls 6,$4 ; 6,8$ e 7,2, perfil $C$, pl > 8,5 e perfil D, pls 5,8; 6,2 e 6,6. Cada isoforma tem um componente majoritário que é específico para cada perfil (MOURA-CAMPOS et al., 1995). Souza et al. (1997) utilizaram ELISA de captura para estudar reação de diferentes isoformas de gp43 com soros de pacientes com PCM. Os resultados obtidos mostram que as isoformas com pls similares (perfis $A$ e D) não apresentaram diferença significativa quanto a reatividade usando como padrão o perfil de isoforma $A$. O perfil de isoforma $C$, mostrou uma redução significativa na reatividade e $B$ mostrou-se mais reativo.

O gene da gp43 foi clonado por Cisalpino et al. (1996), sendo caracterizado por um fragmento de $1,329 \mathrm{~Kb}$, dois exons e um intron. Este foi o primeiro gene de $P$. 
brasiliensis a ser sequenciado e expresso em bactéria como proteínas recombinantes de fusão. Estas proteínas que representavam diferentes regiões da gp43 reagiram positivamente com antisoro policlonal de coelho, monoespecífico antigp43 e com soros de pacientes com PCM. O antisoro gerado em coelho contra a proteína recombinante de fusão reconheceu especificamente a proteína nativa em "imunoblotting" do filtrado de cultura de $P$. brasiliensis.

Sabe-se que alterações de temperatura afetam o metabolismo de RNA, incluindo o processamento e degradação do mRNA. Considerando-se a necessidade de adaptação a choques térmicos para a transição morfológica de $P$. brasiliensis foi concluído que a presença do íntron no DNA do fungo pode implicar numa regulação transcricional. Nos fungos dimórficos a adaptação ao novo ambiente requer respostas ao nível dos genes e sequências de DNA contendo introns poderiam ter papel vital nesta adaptação (DI LALLO et al., 1994).

A descoberta de que a gp43 é o antígeno imunodominante responsável pelas reações de hipersensibilidade tardia do antígeno de Fava-Neto, a qual foi feita por Rodrigues e Travassos (1994). Reações intradérmicas em humanos foram feitas posteriormente utilizando a gp43 purificada (SARAIVA et al., 1996).

Em face desses resultados que associavam a gp43 a uma resposta imune celular do tipo T-CD4+ além da humoral, Taborda et al. (1998) mapearam os epitopos que medeiam esta resposta imune. Os autores demonstraram que um peptídeo de 15 aminoácidos, denominado P10 (resíduos 181-195 do gene da gp43) (IWAI, 2003), é responsável pela ativação de linfócitos $T$ e proteção de camundongos BALB/C contra PCM. Neste trabalho, camundongos BALB/C foram imunizados com gp43 ou P10, em três doses, a primeira em uma das patas de cada animal. Quinze dias depois, a dosagem foi repetida, por via subcutânea, na cauda dos animais. Quinze dias após a primeira imunização foi realizada a segunda, por via intraperitoneal. Quinze dias após a total imunização, os animais foram infectados, por via intratraqueal, com leveduras da cepa virulenta Pb18 de P. brasiliensis. Após 1 e 3,5 meses os animais foram sacrificados e realizou-se a contagem de CFUs em 
pulmão, baço e fígado. Os resultados obtidos com o grupo sacrificado após 3,5 meses mostraram que o grupo controle (não imunizado) apresentou pelo menos 200 vezes mais CFUs no pulmão. A disseminação no baço e no fígado observado nos camundongos controles foi abolida nos animais imunizados com P10 e muito reduzida nos animais imunizados com gp43.

A sequência do peptídeo P10 mostra-se bem conservada conforme estudo da análise do polimorfismo da gp43 feito por Morais et al. (2000). As sequências mais polimórficas foram encontradas em $\mathrm{Pb} 2$ (isolado 1925), $\mathrm{Pb} 3 \mathrm{e} \mathrm{Pb4}$, as quais codificam uma proteína básica, com pl em torno de 8,0. As mesmas sequências foram filogeneticamente distantes das demais e, todos estes isolados foram de pacientes com PCM pulmonar. Um resultado importante obtido neste trabalho foi que nenhuma das substituições no gene da gp43 ocorreu no epítopo P10 para células TCD4+.

Segundo Taborda et al. (1998) proteínas nativas ou recombinantes, ou fragmentos de ambas, podem induzir proliferação de linfócitos $T$ em animais sensibilizados com as mesmas, mas esta propriedade pode ou não resultar em proteção durante a infecção. Em $P$. brasiliensis o peptídeo $\mathrm{P} 10$ provocou uma forte proteção mediada por imunidade celular, pois se verificou a liberação de IFN- $\gamma$ por população de linfócitos Th-1. O IFN- $\gamma$ tem sido relatado como ativador de macrófagos em infecções fúngicas proporcionando atividade fungicida em $P$. brasiliensis e B. dermatitidis (BRUMMER et al., 1988a; BRUMMER et al., 1988b). Camundongos com mutação no gene para receptor de IFN- $\gamma$ (HUANG et al., 1993) são altamente susceptíveis a infecção por $P$. brasiliensis comparados com animais nativos (TRAVASSOS et al., 2004). Considerando estes resultados, podemos considerar o fragmento $\mathrm{P} 10$ um ótimo candidato à terapia gênica para PCM.

Souza et al. (2001) demonstraram outro modelo de proteção utilizando sequência CpG (dinucleotídeo não metilado) também conhecida como sequência imunoestimulatória (ISS), descrito como seqüência bacteriana com propriedade imunomoduladora e estimuladora de Th-1. Foram observadas várias seqüências 
CpG não metiladas em $P$. brasiliensis, uma delas foi sintetizada e utilizada na imunização de camundongos e para testes de fagocitose "in vitro".

Os resultados mostraram que macrófagos obtidos de camundongos B10.A, quando estimulados com ISS de $P$. brasiliensis, obtiveram um aumento em sua atividade fagoccítica. Nos testes "in vivo" foi observado um significante aumento de IFN- $\gamma$ no soro de camundongos imunizados com DNA de $P$. brasiliensis, mas não foi observada produção de IL-4. Considerando que a linhagem de camundongos B10.A é susceptível a apresentar uma resposta predominante Th-2, e que os resultados "in vivo" mostraram um decréscimo na produção de anticorpos anti-gp43, a análise feita dos isotipos de anticorpos (IgG2a e $\lg G 2 b$ ) e citocinas produzidas sugeriram uma modulação Th-1 nestes animais susceptíveis.

De acordo com Cunha et al. (2002) fatores conhecidos como HSP (heat shock protein) também desempenham papel protetor contra doenças infecciosas (MACCHIA et al., 1993; QUIJADA et al., 1996) e também membros da família das HSP participam em vários processos celulares incluindo atividade como chaperonas (FEDER e Hoffman, 1999; HARTL et al., 1996). Em adição a este papel central na transferência de peptídeos através da membrana celular, as HSPs são reconhecidas como importantes moléculas na modulação do sistema imune (DE MAIO, 1999). Um dos membros da família das HSPs, a HSP60 tem demonstrado ser o maior antígeno imunodominante em parasitas e um alvo das respostas humoral e mediadas por células durante infecções (GARBLE, 1992). Respostas imunes para HSP têm sido observadas em infecções causadas por bactérias, protozoárias e em modelos experimentais de infecção por fungos (COHEN e Young, 1991; SCHOEL et al., 1996; SHINNICK, 1991; YOUNG, 1990). Vacinação com HSP60 recombinante em camundongos, por via intranasal, induz proteção contra Histoplasma capsulatum, via resposta imune celular (GOMEZ, et al., 1995).

Cunha et al. (2002) mostraram que a HSP60 recombinante de $P$. brasiliensis foi reconhecida por 72 soros de um total de 75 pacientes com PCM e a sugerem como opção para teste diagnóstico. Outra HSP descrita em $P$. brasiliensis é a HSP 
70 (SILVA et al., 1999), sua liberação é induzida, em leveduras, a $42^{\circ} \mathrm{C}$, e durante a transformação da fase micelial para levedura do fungo.

\subsection{Vacinas humanas e terapia gênica}

A sequência de DNA codificante do peptídeo P10 e/ou da HSP60 pode ser utilizada como vacina de DNA contra a PCM, assim como a utilização de um vetor contendo a sequência para expressão de IL-12 possibilitaria um estudo mais completo no combate à $\mathrm{PCM}$, por ser esta interleucina pró-inflamatória e fundamental na resposta imune-celular contra a PCM.

O uso de vacinas no controle de doenças infecciosas vem de longa data (PLOTIKIN e PLOTIKIN, 1999). Existem indícios de que os chineses já praticavam vacinação contra varíola desde o século 16 , um século antes dos estudos de Edward Jenner, publicados em 1798, onde foi descrita a imunidade adquirida contra varíola, de pessoas que manipularam vacas com "cowpox", Neste trabalho, "Variolae Vaccinae" foi descrito que a forma bovina da varíola poderia ser passada diretamente de uma pessoa infectada para outra, promovendo uma inoculação em larga escala, independente das epidemias em vacas. Daí nasceu a palavra vacina, derivada da palavra vaca (em latim, vacca) em homenagem ao trabalho de Edward Jenner.

Passados 87 anos, Pasteur realizou a primeira vacinação em humanos contra a raiva. Neste período foram desenvolvidos os fundamentos de atenuação e virulência, graças a experimentos como o de Pasteur em 1879, Pasteur deixou uma cultura de Pasteurella multocida (causadora de cólera em galinhas) exposta ao ar por um longo período, em seu retorno notou que a cultura estava atenuada e promoveu imunidade contra o organismo virulento. Este trabalho foi publicado em 1880 e gerou grande interesse. Também surgiu, neste período, a idéia de reforço vacinal, pois sabia-se que a imunidade das pessoas imunizadas durava um certo tempo, só não se conhecia quanto e porquê. 
Em 1877, Pasteur iniciou pesquisas com antrax, nesta mesma época Robert Koch descobriu que este bacilo sobrevivia indefinidamente como forma de esporo. Pasteur fez repetidas inoculações em carneiros, cabras e vacas, com antrax atenuado. Após esta vacinação, os animais imunizados e os não vacinados foram inoculados com antrax virulento. Os carneiros e cabras não-vacinados morreram, as vacas sobreviveram, mas permaneceram doentes. Com este experimento teve início uma nova era na história das vacinas.

A vacina contra raiva foi administrada em humanos pela primeira vez em 1885, desta data em diante, as técnicas para produção de vacinas evoluiram rapidamente. Em 1886, Edmund Salmon e Theobald Smith publicaram um trabalho sobre vacina contra cólera, com vírus morto por calor, este princípio foi utilizado mais tarde para produção de vacinas contra tifo, cólera e peste bubônica. Em paralelo a estas descobertas, trabalhos na área de imunologia começaram a ter grande importância, como o de Elie Metchnikoff que publicou em 1884 a primeira teoria sobre imunidade celular, onde surgiu o termo fagócitos, neste trabalho o autor não apreciava o papel do soro e plasma na imunidade.

Shibasaburo Kitasato e Alexandre Yersin, trabalhando independentemente, descobriram em 1894 o bacilo causador da peste, Pasteurella pestis. Com Albert Calmette e Amédée Borelle, Yersin desenvolveu a vacina atenuada contra este bacilo para animais, mas foi Waldemar Haffkine quem deu visibilidade a esta descoberta, quando foi à Índia trabalhar com vacina de cólera, houve um surto de peste bubônica em Bombaim e Haffkine utilizou sua vacina contra peste para imunizar mais de 8000 pessoas em poucas semanas, foi a primeira vez que esta vacina foi utilizada em humanos, por um tempo, o pesquisador foi considerado um herói, porém em 1902, 19 pessoas morreram por contaminação da vacina utilizada o que causou o encerramento da carreira científica de Haffkine.

John Snow descobriu entre 1848 e 1849 que a cólera era transmitida por contaminação da água, mas não conhecia a identidade do contaminante. Esta questão foi solucionada por Robert Koch, que isolou o Vibrio cholerae em 1883. Em 
1896 Kolle desenvolveu a vacina contra cólera de vírus morto por calor. O vírus foi cultivado em ágar, suspenso em solução salina e aquecido a $50{ }^{\circ} \mathrm{C}$ por alguns minutos, $56{ }^{\circ} \mathrm{C}$ por uma hora e adicionou fenol a $0,5 \%$.

Em 1888 Roux e Yersin demonstraram que o bacilo causador da difteria produzia uma toxina poderosa, dois anos depois, Emil Von Behring e Kitasato publicaram resultados que mostraram a presença de antitoxinas em soro de animais previamente infectados com baixas doses de bacilo. Estas antitoxinas neutralizavam a toxina diftérica em cultura. Em dezembro de 1891, uma criança com difteria foi a primeira a ser tratada com antitoxina. No começo do século 20 , a inativação de toxina diftérica e outras toxinas bacterianas levaram ao desenvolvimento dos primeiros toxóides, o diftérico e o tetânico. Em 1923, Alexander Glenny e Barbara Hopkins mostraram que a toxina diftérica poderia ser transformada em toxóide por tratamento com formalina. No mesmo ano, Gaston Ramon padronizou a produção de toxóide diftérico adicionando formalina e incubando a mistura a $37{ }^{\circ} \mathrm{C}$ por algumas semanas. Em 1926 Ramon e Christian Zoeller iniciaram o uso da toxina tetânica produzida da mesma forma, para vacinação humana. Em 1927, após triagem com crianças desde 1921, foi iniciada a vacinação oficial contra tuberculose. O preparo da vacina foi realizado com o bacilo de Calmette-Guérin (BCG) durante 13 anos de atenuação, por 230 passagens em cultura.

Desta época em diante, houve o desenvolvimento de diversas vacinas, que foram classificadas de acordo com a forma de produção, entre elas destacam-se as vacinas de primeira geração, que são as produzidas por patógenos atenuados como Varíola (1798), BCG (1921), Sarampo (1962), Pólio-Sabin (1950), Febre Tifóide (1972); e as de patógenos inativados como Coqueluche (1936), Gripe, Encefalite, Raiva, Pólio-Salk. Em seguida foram desenvolvidas as vacinas de segunda geração produzidas a partir de frações celulares e produtos do metabolismo como Difteria (1923), Tétano (1927), Pertussis (1984). Hoje são produzidas as vacinas de terceira geração como a de hepatite $B$; estas vacinas são desenvolvida através do conceito de vacinologia reversa que nasceu do desdobramento da pesquisa em genômica de microrganismos visando a identificação de antígenos protetores, são construídas através da combinação de informática e ensaios de expressão e imunização. 
Segundo Eck e Wilson (1996), graças aos avanços na biologia molecular e celular, foram descritas as proteínas mediadoras de muitos processos patológicos enquanto a tecnologia de DNA permite um acesso rápido aos genes que controlam estes eventos. O tamanho, a complexidade e a inacessibilidade celular destas proteínas tornam impossível à transferência ou a modificação por meios farmacológicos. A terapia gênica supera estas barreiras pela introdução seletiva de DNA recombinante nos tecidos, de modo que, as proteínas biologicamente ativas podem ser sintetizadas dentro das células cuja função deve ser alterada. Como tal, a transferência do DNA recombinante tornou-se fundamental em todas as estratégias de terapia gênica. Inúmeros sistemas de transferência de DNA foram desenvolvidos com base em vias de ciclo de vida dos vírus, encapsulamento de lipossomos, injeção direta e formação de complexos com proteínas carreadoras. Embora originalmente planejado como um tratamento para defeitos monogênicos hereditários constatou-se que a terapia gênica tem aplicações em doenças adquiridas como câncer, doenças cardiovasculares e moléstias infecciosas.

A aplicação de terapia gênica em distúrbios adquiridos ocorreu mais rapidamente do que em defeitos monogênicos, por vários motivos, dentre as razões importantes está o fato de ter sido difícil obter a expressão, a longo prazo, do gene (meses ou anos), que é provavelmente necessária para tratar doenças genéticas. A disponibilidade de um grande número de pacientes candidatos com distúrbios adquiridos possivelmente fatais (sobretudo câncer e AIDS) fornece um cenário clínico para o desenvolvimento de novas estratégias de transferência de DNA que poderão ser aplicadas, mais tarde, aos distúrbios hereditários. Em oposição às doenças hereditárias, nas quais um defeito genético já foi bem caracterizado, a maioria das aplicações de terapia gênica em doenças adquiridas, a base molecular da doença é menos compreendida. Em vez de corrigir um defeito subjacente conhecido, o enfoque tem sido adicionar novas funções moleculares que consigam mudar o curso da doença, ou bloquear uma função existente.

O sistema ideal de transferência de DNA seria aquele que aceitasse uma grande variação de tamanho de DNA inserido, fosse disponível em forma concentrada, fosse facilmente produzido e pudesse ser dirigido para tipos 
específicos de células, não permitindo a replicação do DNA, dando uma expressão em longo prazo do gene, e não fosse tóxico nem imunogênico. Nenhuma das tecnologias de transferência é perfeita com relação a nenhum destes tópicos. Entre as tecnologias aplicadas destacam-se as de transferência de DNA através de vetores virais como, por exemplo, os vetores retrovirais que são os mais aplicados e oferecem potencial de expressão em longo prazo, porém, sua aplicação é limitada a células em divisão e sua purificação e concentração são complicadas devido à instabilidade do vírus. Os vetores de adenovírus são capazes de transduzir em amplo espectro de tecidos humanos, mas são limitados por sua duração de expressão do transgene relativamente curta. $O$ vírus adeno-associado tem muitas das características desejáveis dos retrovírus e adenovírus, ele é capaz de se integrar eficientemente ao genoma de células que não se dividem e é estável a uma variedade de manipulações químicas e físicas, a limitação do seu uso está na dificuldade de produzi-lo em grandes quantidades.

Devido às limitações potenciais dos vetores virais, foram desenvolvidos agentes não-virais para mediar à captação celular de DNA exógeno. Estes sistemas de transferência de DNA que incluem DNA de plasmídeo não-associado, complexos DNA lipossomo, complexos DNA-proteína e partículas de ouro revestidas com DNA são construídas a partir de componentes conhecidos. Portanto, sua composição, ao contrário de virions complexos, é bem definida. Além do mais, sua formação é tecnicamente mais fácil do que a dos vírus e, em muitos casos, esses sistemas de endereçamento de DNA podem ser produzidos sem a necessidade de cultura de células.

Diferentes vias de administração podem ser utilizadas, como a intramuscular ou intradérmica, com uso de equipamentos sofisticados ou simples injeção. A rota ideal dependerá de vários fatores como tamanho do animal, antígeno a ser expresso e proteção adquirida contra a doença. A melhor escolha pode ser determinada empiricamente (DAVIS, 2000). 
Vacinas de DNA, utilizando plasmídeos como vetores, têm demonstrado ótimos resultados na proteção contra doenças infecciosas, quando testadas em modelos experimentais. Rogers et al. (1999) construíram vacinas baseadas em sequência de quatro antígenos de Plasmodium vivax, as construções induziram altos níveis na expressão de anticorpos específicos em camundongos imunizados. Outros exemplos experimentais podem ser citados como a proteção obtida em camundongos BALB/c, contra $P$. yoelli, imunizados com plasmídeos contendo o gene da HSP60 (SANCHEZ et al., 2001), neste caso, a proteção foi conseguida com a conjunta administração de GMC-SF murino. Proteção parcial contra Leishmania mexicana pode ser obtida em camundongos BALB/c após a imunização com plasmídeos contendo genes para os antígenos gp63 de Leishmania mexicana e gp46 de L. amazonensis (DUMONTEIL et al., 2003).

Estudos de tolerância, segurança e resposta imune em humanos têm sido realizados para verificar a viabilidade do uso de vacinas de DNA. Le et al. (2000) realizaram imunizações em voluntários adultos, saudáveis. Os voluntários receberam vacinação de diferentes dosagens de plasmídeo contendo a sequência para expressão de uma proteína de $P$. falciparum (PfCSP), foram acompanhados por 12 meses e receberam três injeções por via intramuscular. Nenhum dos voluntários apresentou significante alteração quanto a sintomas sistêmicos ou de reação local. Todos tiveram ótima resposta imune celular e apresentaram anticorpos específicos ao antígeno administrado.

Todos estes resultados mostram o quanto é viável a vacinação por DNA e seu futuro promissor quanto à aplicação desta terapia em diferentes doenças infecciosas.

A eficiência de vacinas de DNA pode ser aumentada se for adicionado um vetor contendo a sequência do gene para expressão de IL-12. Martin et al. (2003) demonstraram a construção de um plasmídeo contendo o gene de uma proteína de 35.000MW comum a Mycobacterium avium e $M$. leprae (ausente em $M$. tuberculosis). Camundongos imunizados com este vetor apresentaram significante 
proteção quando infectados com M. avium e M. leprae, porém, o nível de proteção foi equivalente ao obtido com a vacina convencional (BCG). A interleucina 12 é essencial para promover a diferenciação de linfócitos T-CD4 em secretores de interferon-gama. Co-imunização de camundongos com vetor contendo as cadeias para IL-12 murina e vetor contendo a sequência para a proteína de 35 kDa ativaram células $\mathrm{T}$, a proteção obtida foi superior a conseguida somente com a vacina de DNA. Desta forma, o plasmídeo contendo gene para IL-12 agiu como um adjuvante no aumento da proteção conseguida com a vacina de DNA sobre a tradicional. Jiang et al. (1999), também testaram co-imuniação com um antígeno de Coccidioides immitis conhecido como Ag2 e IL-12, a proteção obtida com a co-imunização foi superior, quando comparada com a oferecida pelos dois fatores, separadamente administrados em camundongos BALB/c.

O primeiro trabalho de imunização contra PCM utilizando vacinas plasmidiais foi realizado por Pinto et al. (2000). Camundongos BALB/c foram imunizados por via intradérmica e intramuscular com o plasmídeo pVR1012 contendo o gene da gp43. O protocolo seguido incluiu quatro imunizações em intervalos de duas semanas, e posterior infecção com $P$. brasiliensis. A rota intramuscular apresentou os melhores resultados, nos camundongos imunizados observou-se resposta imune celular via linfócitos T e B, altos títulos de anticorpos, e não foram encontradas células fúngicas em órgãos como pulmão, fígado e baço. Células linfóides destes camundongos imunizados foram re-estimuladas "in vitro" com gp43 e produziram quantidades substanciais de IL-2 e IFN- $\gamma$, porém IL-4, IL-5, IL-10 e IL-12 não foram detectadas. A alta concentração IFN- $\gamma$ manteve-se "in vivo" e "in vitro" por um longo período, sinalizando a grande proteção obtida com a imunização realizada, estes altos títulos só decresceram a partir do $6^{\circ}$ mês pós-imunização.

A alta incidência de reação de sensibilidade intradérmica (60-75\%) em população adulta de áreas endêmicas (RESTREPO-MORENO, 1994) aponta para a relevância da PCM na América do Sul, onde se considera que aproximadamente 10 milhões de pessoas estejam infectadas e até $2 \%$ delas pode desenvolver a doença (McEWEN et al., 1995). 
Em nosso trabalho utilizamos vetores plasmidiais contendo a sequência de DNA para expressão de P10, IL-12 ou HSP60. A imunização de camundongos $B A L B / c$ e B10.A foi realizada por via intramuscular em diferentes combinações dos fatores expressos. Este estudo teve como meta disponibilizar uma nova ferramenta de combate a paracoccidioidomicose, e esperamos que esta ferramenta possibilite, futuramente, um tratamento auxiliar ao farmacológico tradicional, proporcionando uma recuperação mais breve aos pacientes infectados com $P$. brasilie 


\section{CONCLUSÔES}

6.1 Os plasmídios contendo inserto para expressão de peptídeo P10, IL-12 e HSP60 foram eficazes no combate à PCM experimental, levando à redução de carga fúngica nos pulmões dos camundongos previamente vacinados.

6.2 O conjunto de vetores para expressão de P10 e IL-12 apresentou os melhores resultados na vacinação preventiva. Esses vetores, quando associados ao vetor para expressão de HSP60, mostraram efeito aditivo na proteção obtida.

6.3 Ensaios terapêuticos utilizando o conjunto de vetores para expressão de IL-12 e P10 para tratamento de camundongos BALB/c, resistentes e B10.A, susceptíveis, apresentaram diminuição da contagem de UFC e resposta do padrão Th1, com produção de IFN- $\gamma$ e IL-12.

6.4 Os ensaios terapêuticos com camundongos B10.A resultaram em melhor proteção quando comparados com os ensaios para BALB/c.

6.5 Grupos de camundongos B10.A submetidos à ensaio terapêutico por 5 meses, apresentaram ótimos resultados para o tratamento com o conjunto de vetores P10 e IL-12. A terapêutica permitiu a completa recuperação dos animais com mínima carga fúngica, reestruturação da arquitetura pulmonar e equilíbrio do sistema imune. 


\section{REFERÊNCIAS BIBLIOGRÁFICAS}

ADLER-MOORE, J.; PROFFITT T. Ambisome: liposomal formulation, structure, mechanism of action and pre-clinical experience. J. Antimicrob. Chemother., v.49, p.121-30, 2002.

AJELLO, L. POLONELLI, L. Imported paracoccidioidomycosis, a puclic health problem in non-endemic areas. Eur. J. Epidemiol., v. 1, p. 160-165, 1985.

ALBORNOZ, M. B. Isolation of Paracoccidioides brasiliensis from rural soil in Venezuela. Sabouraudia, v. 9, p. 248-53, 1971.

ALMEIDA, I. C.; NEVILLE, D. C.; MEHLERT, A.; TREUMMAN, A.; FERGUSON, M. A.; PREVIATO, J. O.; TRAVASSOS, L. R. Struture of the N-linked oligosaccharide of the main diagnostic antigen of the pathogenic fungus Paracoccidioides brasiliensis. Glycobiology, v. 6, p. 507-515, 1996.

ALMEIDA, F. Estudos comparativos do granuloma coccidióidico nos Estados Unidos e no Brasil. Novo gênero para o parasito brasileiro. An. Fac. Med. São Paulo, v. 5, p. 125-141, 1930.

ALMEIDA, S. R.; UNTERKIRCHER, C. S.; CAMARGO, Z. P. Involvement of the major glycoprotein (gp43) of Paracoccidioides brasiliensis in attachment to macrophages. Med. Mycol., v. 36, p. 405-411, 1998.

ARRUDA, C.; FRANCO, M. F.; KASHINO, S. S.; NASCIMENTO, F. R.; FAZIOLI, R. A.; VAZ, C. A.; RUSSO, M.; CALICH, V. L. Interleukin-12 protects mice against disseminated infection caused by Paracoccidioides brasiliensis but enhances pulmonary inflammation. Clin. Immunol., v. 103, p.185-195, 2002.

ARRUDA, C.; VALENTE-FERREIRA, R. C.; PINA, A.; KASHINO, S. S.; FAZIOLI, R. A.; VAZ, C. A.; FRANCO, M. F.; KELLER, A. C.; CALICH, V. L. Dual role of interleukin-4 (IL-4) in pulmonary paracoccidioidomycosis: endogenous IL-4 can induce protection or exacerbation of disease depending on the host genetic pattern.

Infect. Immun., v. 72, p. 3932-3940, 2004.

Normas ABNT:

ASSOCIAÇÃO BRASILEIRA DE NORMAS TÉCNICAS. NBR 6023: informação e documentação: referências e elaboração. Rio de Janeiro, 2002. 
BAGAGLI, E.; SANO, A.; COELHO, K.I .; ALQUATI, S.; MIYAJI, M.; CAMARGO, Z. P.; GOMES, G. M.; FRANCO, M.; MONTENEGRO, M. R. Isolation of Paracoccidioides brasiliensis from armadillos (Dasypus noveminctus) captured in an endemic area of paracoccidioidomycosis. Am. J. Trop. Med. Hyg., v. 584, p. 505512, 1998.

GARREN, H.; ROBINSON, W. H.; KRASULOVA, E.; HAVRDOVA, E.; NADJ, C.; SELMAJ, K.; LOSY, J.; NADJ, I.; RADUE, E.; KIDD, B. A.. GIANETTONI, J.; TERSINI, K.; UTZ, P. J. VALONE, F.; STEINMAN, L.; AND BHT-3009 STUDY GROUP. Phase 2 trial of a DNA vaccine encoding myelin basic protein for multiple sclerosis. Ann. Neurol., v. 63, p. 611-620, 2008.

BARBOSA, M. S.; BAO, S. N.; ANDREOTTI, P. F.; De FARIA, F. P.; FELIPE, M. S.; Dos SANTOS FEITOSA, L.; MNEDES-GIANNINI, M. J.; SOARES, C. M. Glyceraldehyde-3-phosphate dehydrogenase of Paracoccidioides brasiliensis is a cell surface protein involved in fungal adhesion to extracellular matrix proteins and interaction with cells. Infect. and Immun., v. 74, n. 1, p. 382-389, 2006.

BITTENCOURT, A. L.; ANDRADE, J. M.; FILHO, S. P. C. Paracoccidioidomycosis in a four-years-old boy. Mycopathology, v. 93, p. 55-59, 1986.

BLUMER, S. O.; JALBERT, M.; KAUFMAN, L.. Rapid and reliable method for production of a specific Paracoccidioides brasiliensis immunodiffusion test antigen. $\mathbf{J}$. Clin. Microbiol., v. 19, n. 3, p. 404-407, 1984.

BORDIER, C. Phase separation of integral membrane proteins in Triton $\mathrm{X}-114$ solution. J. Biol. Chem., v. 256, n. 4, p. 1604-1607, 1981.

BORELLI, D. Some ecological aspects of paracoccidioidomycosis. In: Pan American Health Organization. Scientific Publication. Washington, DC: PAHO, 1972. v. 254, p. 59-64.

BORGES-WALMSLEY, M. I.; CHEN, D.; SHU, X.; WALMSLEY, A. R. The pathobiology of Paracoccidioides brasiliensis. Trends Microbiol., v. 10, n. 2, 2002.

BRUMMER, E.; CASTAÑEDA, E.; RESTREPO, A. 1993. Paracoccidioidomycosis un Update. Clin. Microbiol. Rev., v. 6, p. 89-117, 1993.

BRUMMER, E.; HANSON, L. H.; RESTREPO, A.; STEVENS, D. A. In vivo and in vitro activation of pulmonary macrophages by IFN- $\gamma$ for enhanced killing of 
Paracoccidioides brasiliensis or Blastomyces dermatidis. J. Immunol., v. 140, p. 2786-2789, 1988a.

BRUMMER, E.; HANSON, L. H.; STEVENS, D. A. IFN- $\gamma$ activation of macrophages for killing Paracoccidioides brasiliensis evidence for nonoxidative mechanisms. Int. J. Immunopharmacol. v. 10, p. 945-952, 1988 b.

BUISSA-FILHO, R.; PUCCIA, R.; MARQUES, A. F.; PINTO, F. A.; MUNHOZ, J. E.; NOSANCHUK, J. D.; TRAVASSOS, L. R.; TABORDA, C. P. The monoclonal antibody against the major diagnostic antigen of Paracoccidioides brasiliensis mediates immune protection in infected BALB/c mice challenged intratracheally with the fungus. Infect. Immun., v. 76, p. 3321-3328, 2008.

BURNIE, J. P.; CARTER, T. L.; HODGETTS, S. J.; MATTHEWS, R. C. Fungal heatshock proteins in human disease. FEMS Microbiol. Rev., v. 30, p. 53-88, 2006.

CALICH V. L. G.; SINGER-VERMES, L. M.; SIQUEIRA A. M. Susceptibility and resistance of inbred mice to Paracoccidioides brasiliensis. Br. J. Exp. Pathol., v. 66, p. 585-594, 1985.

CALICH V. L. G.; SINGER-VERMES L. M.; RUSSO M. Immunogenetics in paracoccidioidomycosis. In: FRANCO, M. et al. (Ed.). Paracoccidioidomycosis. Boca Raton: CRC Press. 1994, p.151-173.

CALICH, V. L.; KASHINO, S. S. Cytokines produced by susceptible and resistant mice in the course of Paracoccidioides brasiliensis infection. Braz. J. Med. Biol. Res., v. 31, n. 5, p. 615-623, 1998.

CAMARGO Z. P.; UNTERKIRCHER C.; CAMPOY S. P.; TRAVASSOS L. R. Production of Paracoccidioides brasiliensis exoantigens for immunodiffusion tests. J. Clin. Microbiol., v. 26, p. 2147-2151, 1988.

CAMARGO, Z. P.; TABORDA, C. P.; RODRIGUES, E. G.; TRAVASSOS, L. R. The use of cell free antigens of Paracoccidioides brasiliensis in serological tests. J. Med. Vet. Mycol., v. 29, p. 31-38, 1991.

CASADEVALL, A. Antibody immunity and invasive fungal infections. Infect. Immun., v. 63, p. 4211-4218, 1995. 
CHIARELLA, P.; MASSI, E.; DE ROBERTIS, M.; FAZIO, V. M.; SIGNORI, E. Strategies for effective naked-DNA vaccination against infectious diseases. Recent Patents Anti-infect. Drug Disc., v. 3, n. 2, p. 1-9, 2008.

CHICAMORI, T.; SAKA, S.; NAGANO, H.; SAEKI, S.; LACAZ, C. S.; RODRIGUES, M. C.; CASSAGUERRA, C. M.; BRACCIALLI, M. L. Paracoccidioidomycosis in Japan, report a case. Rev. Inst. Med. Trop. São Paulo, v. 26, p. 267-271, 1984.

CISALPINO, P. S.; PUCCIA, R.; YAMAGUCHI, L. M.; CANO, M. L.; SILVEIRA, J. F.; TRAVASSOS, L. R. Clonig, characterization and epitope expression of the major diagnostic antigen of Paracoccidioides brasiliensis. J. Biol. Chem., v. 271, p. 45534560, 1996.

CLEMONS, K. V.; FELDMAN, D.; STEVENS, D. A. Influence of oestradiol on protein expression and methionine utilization during morphogenesis of Paracoccidioides brasiliensis. J. Gen. Microbiol., v. 135, p.1607-17, 1989.

COHEN, L. R.; YOUNG, D. B. Autoimmunity, microbial immunity and the immunological homusculus. Immunol. Today, v. 12, p. 105-110, 1991.

CONTI-DIAZ, I. A.; MACKINNON, J. E.; CALEGARI, L.; CASSERONE, S. Estudio comparativo de la inmunoelectroforesis (IEF) y de la inmunoelectroosmoforesisinmudifusion (IEOF-ID) aplicadas al diagnóstico de la paracoccidioidomicosis. Mycopathology, v. 63, p. 161-165, 1978.

COUTINHO, Z. F.; SILVA, D.; LAZERA, M.; PETRI, V.; OLIVEIRA, R. M.; SABROSA, P. C.; WANKE, B. Paracoccidioidomycosis Mortality in Brazil (19801985). Cad. Saúde Pública, v.18, n. 5, p. 1441-1454, 2002.

CUNHA, D. A.; ZANCOPÉ-OLIVEIRA, R. M.; SOARES FELIPE, M. S.; SALEMIZAAC, S. M.; DEEP JR., G. S.; SOARES, C. M. A. Heterologous expression, purification, and immunological reactivity of a recombinant HSP60 from Paracoccidioides brasiliensis. Clin. Diag. Lab. Immunol., v. 9, n. 2, p. 374-377, 2002.

DAVIS, H. L. Intramuscular and intradermal injection of DNA vaccines in mice and primates. In: LOWRIE, D.B.; WHALEN, R.G. (Ed). Methods in molecular medicine, v. 29, DNA vaccines: methods and protocols. Totowa, N.J: Humana Press, 2000. p. 71-77. 
DE MAIO, A. Heat shock proteins: facts, thoughts, and dreams. Shock, v. 11, n. 1, p. 1-12, 1999.

DI LALLO, G.; GARGANO, S.; MARESCA, B. The Histoplasma capsulatum cdc2 gene is transcriptionally regulated during morphologic transition. Gene, v. 140, p. 5157, 1994.

DIAS, M. F.; PEREIRA, A. C.; PEREIRA, A. ALVES, M. S. The role of HLA antigens in the development of paracoccidioidomycosis J. Eur. Acad. Dermatol. Venereol., v. 14, n. 3, p. 166-71, 2000.

DUMONTEIL, E.; RAMIREZ-SIERRA, M. J.; ESCOBEDO-ORTEGON, J.; GARCIAMISS, M. R. DNA vaccines induce partial protection against Leishmania mexicana. Vaccine, v. 21, n. 17-18, p. 2161-2168, 2003.

ECK, S. L.; WILSON, J. M. Terapia Gênica. In: HARDMAN, J. G.; LIMBIRD, L. E.; MOLINOFF, P. B.; RUDDON, R. W.; GOODMAN GILMAN, A. (Ed.). As Bases Farmacológicas da terapêutica. Mexico-DF: McGraw Hill Interamericana, 1996, p. 55-73.

EMANUEL, A.; MILLINGTON, A.; L. Paracoccidioidomicose. Análise de uma casuística hospitalar observada num período de 11 anos no Distrito Federal. An. Bras. Dermatol., v. 58, p. 257-260, 1983.

FARIAS, M. R.; WERNERE, J.; MARQUES, S. A.; MARQUES, M. E.; FRANCO, M.; RIBEIRO, G.; CUSTÓDIO, C. C.; CONDAS, L. A. Z.; BOSCO, S. M. G.; BAGAGLI, E. Canine paracoccidioidomycosis: case report of generalized lynphadenitis. Rev. Inst. Méd. Trop. S. Paulo, v. 47, n. 14, p. 64, 2005.

FAVA-NETTO, C. Estudos quantitativos sobre fixação de complemento na blastomicose sul-americana, com antígeno polissacarídico. Arq. Cir. Clin. Exp., v. 18, p. 197-254, 1955.

FAVA-NETTO, C. Contribuição para o estudo imunológico da blastomicose de Lutz (Blastomicose sul-americana). Rev. Inst. Adolfo Lutz, v.21, p.99-194, 1961.

FAVA-NETTO, C.; CASTRO, R. M.; GONÇALVES, A. P. Ocorrência familiar de blastomicose sul-americana. A propósito 14 casos. Rev. Inst. Med. Trop. São Paulo, v. 7, p. 332-6, 1965. 
FEDER, M. E.; HOFFMAN, G. E. Heat shock proteins, molecular chaperones and the stress response evolutionary and ecological physiology. Annu. Rev. Physiol.; v. 61, p. 243-282, 1999.

FERGUSON, R.; UPTON, M. F. The isolation of Paracoccidioides brasiliensis from a case of South-american blastomycosis. J. Bacteriol., v. 53, p. 376-381, 1974.

FERRI, R. G. Estudo imunoquímico de antígenos intracelulares. Hospital, Rio de Janeiro, v. 59, p. 917-924, 1961.

FORJAZ, M. H. H. Estudo de epidemiologia da paracoccidioidomicose. Rastreamento de áreas endêmicas e de "reservareas" no Brasil, através do traçado do perfil migratório-residencial-profissional, de pacientes diagnosticados em São Paulo. 170 f. Tese (Doutorado em Microbiologia e Imunologia)- Universidade Federal de São Paulo, São Paulo, 1989.

FOUNTAIN, F. F.; SUTHIEFF, W. D. Paracoccidioidomycosis in the United States. Am. Rev. Resp. Dis., v. 99, p. 89-93, 1969.

FRANCO, M.; MONTENEGRO, M. R. G. Anatomia patológica. In: DEL NEGRO, G.; LACAZ, C. S.; FIORELLO A. M. (Ed.). PCM: blastomicose sul-americana, São Paulo: Sarvier, p. 97-117, 1982.

FRANCO, M. Host parasite relationships to paracoccidioidomycosis. J. Med. Vet. Mycol., v. 2, p. 5-18, 1986.

FRANCO, M. et al. Paracoccidioidomycosis. Baillière's. Clin. Trop. Méd. Commun. Dis., v. 4, p. 185-220, 1989.

FRANCO, M. Pathology. In: FRANCO, M. Paracoccidioidomycosis, USA: CRC Press. 1994. p.142-146.

FRANCO, M.; BAGAGLI, E.; SCAPOLIO, S.; LACAZ, C. S. A critical analysis of isolation of Paracoccidioides brasiliensis from soil. Med. Mycol., v. 38, n. 3, p.185191, 2000.

GARBLE, T. R. Heat shock proteins and infection interations of pathogen and host. Experientia, v. 48, p. 635-639, 1992. 
GARCIA, J. P. and HOWERD, D. H. Characterization of antigens from the yest phase of Histoplasma capsulatum. Infect. Immun., v.4, p. 116-125, 1971.

GARCIA, N. M.; DEL NEGRO, G. M.; HEINS-VACCARI, E. M.; DE MELO, N. T.; DE ASSIS, C. M.; LACAZ, C. S. Paracoccidioidomycosis: a new sample isolated from feces of a penguim (Pygoscelis adeliae). Rev. Inst. Med. Trop. São Paulo, v. 35, n. 3, p. 227-235, 1993.

GEZUELE, E. Aislamiento de Paracoccidioides sp. de heces de um pinguino de la Antártida. In: IV INTERNACIONAL SYMPOSIUM ON PARACOCCIDIOIDOMYCOSIS. 1989. Abstract B-2. Caracas, Venezuela.

GOLDANI, L. Z.; MONTEIRO, C. M. C.; DONALDI, E. A.; MARTINEZ, R.; VOLTARELLI, J. C. HLA antigens in Brazilian patients with paracoccidioidomycosis. Mycopathology, v. 114, p. 89-91, 1991.

GOMEZ, B. L.; NOSANCHUK, J. D.; DIEZ, S.; YOUNGCHIM, S.; AISEN, P.; CANO, L. E.; RESTREPO, A.; CASADEVALL, A.; HAMILTON, A. J. Detection of melanin-like pigments in the dimorphic fungal pathogen Paracoccidioides brasiliensis in vitro and during infection. Infect. Immun., v. 69, p. 5760-5767, 2001.

GOMEZ, F. J.; ALLENDOERFER, R.; DEEPE JR., G. S. Vaccination with recombinant heat shock protein 60 from Histoplasma capsulatum protects mice against pulmonary histoplasmosis. Infect. Immun., v. 63, p. 2587-2595, 1995.

GREER, D. L.; RESTREPO, A. La epidemiologia de la paracoccidioidomicosis. Bol. Oficina Sanit. Panam., v. 82, p. 428-445, 1977.

HARTL, F. U. Molecular chaperines in cellular protein folding. Nature, v. 381, p. 571579, 1996.

HILL, H. Z. The function of melanin or six blind people examine an elephant. Bioessays, v.14, p. 49-56, 1992.

HUANG, S.; HENDRICKS, W.; ALTHAGE, A.; HEMMI, S.; BLUETHMANN, H.; KAMIJO, R.; VILCEK, J.; ZINKERNAGEL, R. M.; AGUET, M. Immune response in mice that lack the interferon-gamma receptor. Science, p. 1742-1745, 1993. 
IWAI, L. K.; YOSHIDA, M.; SYDNEY, J.; SHIKANAI-YATSUDA, M. A.; GOLDBERG, A. C.; JULIANO, M. A.; HAMMER, J.; JULIANO, L.; SETTE, A.; KALIL, J.; TRAVASSOS, L. R. and CUNHA NETO, E. In silico Prediction of peptides binding to multiple HLA-DR molecules accurately identifies immunodominant epitopes from gp43 paracoccidioides brasiliensis frequently recognized in primary peripheral blood mononuclear cell responses from sensitized individuals. Mol. Med., v.9, p.209-219, 2003.

IWAI, L. K.; YOSHIDA, M.; SADAHIRO, A.; SILVA, W. R.; MARIN, M. L.; GOLDBERG, A. C.; JULIANO, M. A.; JULIANO, L.; SHIKANAI-YASUDA, M. A.; KALIL, J.; CUNHA-NETO, E.; TRAVASSOS, L. R. T-cell recognition of Paracoccidioides brasiliensis gp43-derived peptides in patients with paracoccidioidomycosis and healthy individuals. Clin. Vaccine Immun., v. 14, n. 4, p. 474-476, 2007.

IZACC, S. M. S.; GOMEZ, F. J.; JESUINO, R. S .A.; FONSECA, C. A.; FELIPE, M. S. S.; DEEPE, G. S.; SOARES, C. M. A. Molecular cloning, characterization and expression of the heat shock protein 60 gene from de human pathogenic fungus Paraciccidioides brasiliensis. Med. Mycol., v. 39, p. 445-455, 2001.

ITO, K.; ITO, K.; SHINOHARA, N.; KATO, S. DNA immunization via intramuscular and intradermal routes using a gene gun provides different magnitudes and durations on immune responses. Mol. Immunol., v. 39, p. 847-854., 2003.

JACOBSON, E. S.; TINNELI, S. B. Antioxidant function of fungal melanin. J. Bacteriol., v. 175, p. 7102-4, 1993.

JIANG C, MAGEE D. M, COX R. A. Coadministration of interleukin 12 expression vector with antigen 2 cDNA enhances induction of protective immunity against Coccidioides immitis. Infect. Immun., v. 67, n. 11, p. 5848-53, 1999.

JONHSON, W.; LANG, C. Paracoccidioidomycosis (South American blastomycosis) in a squirrel monkey (Samiri sciureus). Vet. Pathol., v. 14, p. 552-558, 1996.

KIRKLAND, T. N.; FIERER, J. Genetic control of resistance to Coccidioides immitis: a single gene that is expressed in spleen cells determines resistance. J. Immunol., v.135, p.548-552, 1985.

KNUTSON, K. L.; DISIS M. L. Tumor antigen-specific T helper cells in cancer immunity and immunotherapy. Cancer Immunol. Immunother., v.54, p.721-728. 
LACAZ, C. S.; ULSON, C. M.; SAMPAIO, S. A. P. Ação in vitro da anfotericina B sobre o P. brasiliensis. Rev. Paul. De Med., v. 54, p. 357-360, 1959.

LACAZ, C. S. Fungos, actinomicetos e algas de interesse médico. In: LACAZ, C. S. (Ed.). Compêndio de micologia médica, São Paulo: Sarvier, 1977. p. 229-271.

LACAZ, C. S. Historical evolution of the knowledge on paracoccidioidomycosis and its ethiologic agent. In: FRANCO, M. et al. (Ed.). Paracoccidioidomycosis. Boca Raton: CRC Press, 1994. p. 1-11.

LACAZ, C. S. Paracoccidioidomicose. In: LACAZ, C. S.; PORTO, E.; MARTINS, J. E. C.; HEINS-VACCARI, E. M.; MELO, N. T.(Ed.). Tratado de micologia médica Lacaz, $9^{a}$ ed. São Paulo: Sarvier, 2002, p. 639-729.

LAEMMLI, U. K. Cleavage of structural proteins during the assembly of the head of bacteriophage T4. Nature, v. 227, n. 5259, p. 680-685, 1970.

LE, T. P.; COONAN, K.M.; HEDSTROM, R. C.; CHAROENVIT, Y.; SEDEGAH, M.; EPSTEIN, J. E.; KUMAR, S.; WANG, R.; DOOLAN, D. L.; MAGUINE, J. D.; PARKER, S. E. HOBART, P.; NORMAN, J.; HOFFMAN, S. L. Safely, tolerability and humoral immune responses after intramuscular administration of malaria DNA vaccine to healthy adult volunteers. Vaccine, v. 17,18, n. 18, p. 1893-901, 2000.

LIVONESI, M. C.; SOUTO, J. T.; CAMPANELLI, A. P.; MAFFER, C. M.; MARTINEZ, R.; ROSSI, M. A.; DA SILVA, J. S. Deficiency of IL12p40 subunit determines severe paracoccidioidomycosis in mice. Med. Mycol., v. 12, p. 1-10, 2008.

LONDERO, A. T.; RAMOS, C. D. Paracoccidioidomycosis: A clinical and mycologic study of forty-one cases observed in Santa Maria, RS, Brazil. Am. J. Med., v. 52, p. 771-775, 1972.

LONDERO, A. T. e RAMOS, C. D. Paracoccidioidomicose: estudo clínico-micológico de 260 casos observados no interior do estado do Rio Grande do Sul. J. Peneum., v. 16, p. $129-132,1990$.

LONG, K.H.; GOMEZ, F.J.; MORRIS, R.E.; NEWMAN, S.L. Identification of heat shock protein 60 as the ligand on Histoplasma capsulatum that mediates binding to CD18 receptors on human macrophages. J. Immunol., v. 170, p. 487-494, 2003. 
LOWRIE, D. B.; TASCON, R. E.; BONATO, V. L. D.; LIMA, V. M. F.; FACCIOLI, L. H.; STAVROPOULOS, E.; COLSTON, M. J.; HEWINSON, R. G. ; MOELLING, K.; SILVA, C. L. Therapy of tubercfulosis in mice by DNA vaccination. Nature, v. 400, p. 269-271, 1999.

LUTZ, A. Uma mycose pseudococcidica localisada na boca e observada no Brasil. Contribuição ao conhecimento das hypo-blastomycoses americanas. Braz. Med., v. 22, p.141-144, 1908.

MACCHIA, E. A.; MASSONE, A.; BURRONI, D.; COVACCI, A.; CENSINI, S.; RAPPUOLI, R. The HSP60 protein of Helicobacter pylori struture and immune response in patients with gastroduodenal diseases. Mol. Microbiol., v. 9, p. 645-652, 1993.

MARQUES, A. F.; DA SILVA, M. B.; JULIANO, M. A. P.; TRAVASSOS, L. R.; TABORDA, C. P. Peptide Immunization as an adjuvant to chemotherapy in mice challenged intratracheally with virulent yeasts cells of Paracoccidioides brasiliensis. Antimicrob. Agents Chemother., v. 50, p. 2814-2819, 2006.

MARQUES, A. F.; DA SILVA, M. B.; JULIANO, M. A. P.; MUNHOZ, J. E.; TRAVASSOS, L. R.; TABORDA, C. P. Additive effect of P10 immunization and chemotherapy in anergic mice challenged intratracheally with virulent yeasts of Paracoccidioides brasiliensis. Microb. Infect., v. xx, p. 1-8, 2008.

MARTIN, E.; KAMATH, A.T.; BRISCOE, H.; BRITTON, W. J. The combination of plasmid interleukin-12 with a single DNA vaccine is more effective than Mycobacterium bovis (bacille Calmette-Guerin) in protecting agains systemic Mycobacterium avium infection. Immunology, v. 109, n. 2, p. 308-314, 2003.

MARTINEZ, R.; MALTA M. H. B.; VERCEZE, A. V.; ARANTES, M. R. Comparative efficacy of fluconazole and amphotericin $B$ in the parenteral treatment of experimental paracoccidioidomycosis in the rat. Mycopathologia, v.146, p.131-134, 1999.

MATTOS GROSSO, D.; DE ALMEIDA, S. R.; MARIANO, M.; LOPES, J. D. Characterization of gp70 and anti-gp70 monoclonal antibodies in Paracoccidioides brasiliensis pathogenesis. Infect. Immun., v. 71, n. 11, p. 6534-6542, 2003.

McEWEN, J. G. et al. Experimental murine paracoccidiodomycosis induced by the inhalation of conidia. J. Med Vet. Mycol., v.25, p.165-175, 1987. 
McEWEN, J. G.; GARCIA, A .M.; ORTIZ, B. L.; BOTERO, S.; RESTREPO, A. Search of the natural habitat of Paracoccidioides brasiliensis. Arch. Med. Res., v. 26, p. 305-306, 1995.

MONTENEGRO, M. R. G. Formas clínicas de paracoccidioidomicose. Rev. Inst. Med. Trop. São Paulo, v. 28, p. 203-204, 1986.

MORAES, C. B.; SCHAFFER, G. M. V. Paracoccidioides brasiliensis: virulence and an attempt to induce the dimorphic process with fetal calf serum. Mycoses, v. 45, p. 174-179, 2002.

MORAIS, F. V.; BARROS, T. F.; FUKADA, M. K.; CISALPINO, P. S.; PUCCIA, R. Polymorphism in the gene coding for the immunodominant antigen gp43 from the pathogenic fungus Paracoccidioides brasiliensis. J. Clin. Microbiol., v. 38, n. 11, p. 3960-3966, 2000.

MOSES, A. Fixação de Complemento na Blastomicose. Mem. Inst. Oswaldo Cruz, v. 8, p. 68-70, 1916.

MOURA CAMPOS, M. C.; GESZTESI, J-L.; VICENTINI, A.; LOPES, J. D.; CAMARGO, Z. P. Expression and isoforms of gp43 in different strains of Paracoccidioides brasiliensis. J. Med. Vet. Mycol., v. 33, p. 223-228, 1995.

MUCHMORE, H. G.; MCKOWN, B. A.; MOHR, J. A. Effects of the steroid hormones on the proliferation of Paracoccidioidomicosis braziliensis. Biol. Oficina Sanit. Panam., v. 77, p. 55-70, 1974.

NAIFF, R.; FERREIRA, L.; BARRAET, T.; NAIFF, M.; ARIAS, J. Enzootic paracoccidioidomycosis in armadillos (Dasypus novemcitus) in the State of Para. Rev. Inst. Med. Trop. S. Paulo, v. 28, p. 19-27, 1986.

NEGRONI, P. The Paracoccidioides brasiliensis lives saprophytically in the soil of Argentina. Prensa Med. Argent., v. 53, p. 2381-2, 1966.

NEGRONI, R. Nuevos estudios sobre antígenos para las pruebas serologicas en al blastomicosis sudamericana. Iber. Lat. Am., v. 4, p. 409-416, 1968. 
NICHOLS, W. W.; LEDWITH, B. J.; MANAN, S. V.; TROILO, P.J. Potencial DNA vaccine integration into host cell genome. Ann. N. Y. Acad. Sci., v. 772, p. 30-39, 1995.

NOSANCHUK, J. D.; VALADON, P.; FELDMESSER, M.; CASADEVALL, A. Melanization of Cryptococcus neoformans in murine infection. Mol. Cell. Biol., v.19, p. 745-50, 1999.

PASKO, M. T.; PISCITELLI, S. C.; VAN SLOOTEN, A. D. Fluconazole: a new traizole antifungal agent. Dicp., v.24, p.860-867, 1990.

PELLEGRINO, A.; DE CAPRILES, C. H.; MAGALDI, S.; MONTES DE OCA, I.; RUIZ, M. E.; PEREZ, C.; MATA-ESSAYAG, S. Case report: severe juvenile type paracoccidioidomycosis with hepatitis. C. Am. J. Trop. Med. Hyg. v.68, p.301-303, 2003.

PETRI, W. A. Jr: Antimicrobial agents: Sulfonamides, trimethoprim-sulfamethoxazole, quinolones and agents in urinary tract agents. In: Goodman \& Gilman's the pharmacological basis of therapeutics $\left(10^{\text {th }} \mathrm{ed}\right)$. Hardman Jg, Limbird L. E., Gilman A. G., (Eds.) MacGraw-Hill, New York. v.44, p.1171-1188, 2001.

PINTO, A. R.; PUCCIA, R; DINIZ, S. N.; FRANCO, M. F.; TRAVASSOS, L. R. DNAbased vaccination against murine paracoccidioidomycosis using the gp43 gene from Paracoccidioides brasiliensis. Vaccine, v. 18, n. 26, p. 3050-3058, 2000.

PINTO, M. R.; SÁ, A. C. M.; LIMONGI, C. L.; ROZENTAL, S.; SANTOS, A. L. S.; BARRETO-BERGTER, E. Involvement of peptidorhamnomannan in the interaction of Pseudallescheria boydii and HEp2 cells. Microbes Infect., v. 6, p. 1259-1267, 2004.

PLOTKIN, S. L.; PLOTKIN, S. A. A short history of vaccination. In: PLOTKIN, S. A.; MORTIMER, E. A. (Ed.). Vaccines. 3 ed. Philadelphia: W. B. Saunders Company, p. 1-12, 1999.

PUCCIA, R.; SCHENKMAN, S.; GORIN, P. A. J. and TRAVASSOS, L. R. Exocellular components of Paracoccidioides brasiliensis. Identification of a specific antigen. Infect Immun., v.53, p.193-203, 1986.

PUCCIA, R.; TAKAOKA, D.; TRAVASSOS, R. L. Purification of the $43 \mathrm{kDa}$ glycoprotein from exocellular components excreted by Paracoccidioides brasiliensis. J. Med. Vet. Mycol., v. 29, p. 57-60, 1991b. 
PUCCIA, R.; TRAVASSOS, L. R. The 43kDa glycoprotein from Paracoccidioides brasiliensis immunochemical reactions with sera from patients with paracoccidioidomycosis, histoplasmosis, or Jorge Lobo's disease. J. Clin. Microbiol., v. 29, n. 8, p.1610-1605, 1991a.

PUCCIA, R.; CARMONA, A. K.; GESZTESI, J. L.; JULIANO, L.; TRAVASSOS, L. R. Exocellular proteolytic activity of Paracoccidioides brasiliensis: cleavage of components associated with the basement membrane. Med. Mycol., v. 36, n. 5, p. 345-348, 1998.

PURCELL, A. W.; McCLUSKEY, J.; ROSSJOHN, J. More than one reason to rethink the use of peptides in vaccine design. Nat. Rev., v. 6, p. 404-414, 2007.

QUIJADA, L.; REQUENA, J. M.; SOTO, M.; ALONSO, C. During canine-cutaneous leishmaniosis the anti HSP70 antibodies are specifically elicited by the parasite protein. Parasitology, v. 112, p. 277-284, 1996.

REBELLATO, C. L. K. Estudo de associação entre os antígenos HLA-A, B, C, DR e DQ e a paracoccidioidomicose infecção e a forma crônica da paracoccidioidomicose doença. Dissertação (Mestrado). Universidade Federal do Paraná, Curitiba, 1996.

RESTREPO, A. La puebra de inmunodifusión en el diagnóstico de la paracoccidioidomicosis. Sabouraudia, v. 4, p. 223-230, 1966.

RESTREPO, A. Comportamiento inmunologico de veite pacientes com paracoccidioidomicosis. Ant. Med., v. 17, p. 211-230, 1967.

RESTREPO, A; MONCADA, L. H.; QUINTERO, M. Effect of hidrogen ion concentration and temperature on the growth of Paracoccidioides brasiliensis in soil extracts. Sabouraudia, v. 7, p. 207-215, 1969.

RESTREPO, A.; DROUHET, E. Étude des anticorps precipitants dans la blastomycose sudamericaine par l'analyse immunoeléctroforétique des antigènes de Paracoccidioides brasiliensis. Ann. Inst. Pasteur., v. 119, p. 338-346, 1970.

RESTREPO, A.; ROBLEDO, M.; GUTERREZ, F.; SANCLEMENTE, M. B.; CASTANEDA, E.; CALLE, G. Paracoccidioidomycosis (South American Blastomycosis). A study of 39 cases observed in Medellín, Colômbia. Am. J. Trop. Med. Hyg., v.19, p.68-76, 1970a. 
RESTREPO, A.; GREER D. L.; VASCONCELLOS, M. Paracoccidioidomycosis: A review. Rev. Med. Vet. Mycol., v. 8, p. 97-123, 1973.

RESTREPO, A.; MONCADA, L. H. Characterization of the precipitin bands detected in the immunodiffusion test for paracoccidioidomycosis. Appl. Microbiol., v. 28, p. 138-44, 1974.

RESTREPO, A. Paracoccidioidomicosis. Acta Med. Colomb., v. 3, p. 33-66, 1978.

RESTREPO, A.; ARANGO, M. D. In vitro susceptibility testing of Paracoccidioides brasiliensis to sulfonamides. Antimicrob. Agents Chemother., v.18, p.190-194, 1980.

RESTREPO, A.; STEVENS, D. A.; GOMES, I. et al. Ketoconazole: a new drug for the treatment of Paracoccidioidomycosis. Rev. infec. Dis., v.2, p.633-642, 1980a.

RESTREPO, A.; DE BEDOUT, C.; CANO, L. E.; ARANGO, M. D.; \& BEDOYA, V. Recovery of Paracoccidioides brasiliensis from a partially calcified lymph node lesion by microaerophilic incubation of liquid media. Sabouraudia, v.19, p.295-300, 1981.

RESTREPO F. M.; RESTREPO, M.; RESTREPO, A. Blood groups and HLA antigens in paracoccidioidomycosis. Sabouraudia, v. 21, n. 1, p. 35-35, 1983.

RESTREPO, A.; GOMES I.; CANO, L. E.; ARANGO, M. D.; GUTIERREZ, F.; SANIN, A.; and ROBLEDO, M. A. Treatment of paracoccidioidomycosis with Ketoconazole: a three-year experience. Am. J. Med., v.74, p.48-52, 1983a.

RESTREPO, A. The ecology of Paracoccidioides brasiliensis: a puzzle still unsolved. Sabouraudia, v. 23, p. 232-334, 1985.

RESTREPO-MORENO, A. Ecology of Paracoccidioides brasiliensis. In: FRANCO, M.; LACAZ, C. S.; RESTREPO-MORENO, A.; DEL NEGRO, G. (Ed.). Paracoccidioidomycosis. Boca Raton: CRC Press, 1994. p. 121-130.

RESTREPO, A.; McEWEN, J. G.; CASTANEDA, E. The habitat of Paracoccidioides brasiliensis: how far from solving the riddle? Med. Mycol., v. 39. p. 233-241, 2001. 
RIBEIRO, D. O. Nova terapêutica para blastomicose. Public. Méd. ,São Paulo, v.12, p.36-54, 1940.

ROGERS, W. O.; GOWDA, K.; HOFFMAN, S. L. Construction and immunogenicity of DNA vaccine plasmids encoding four Plasmodium vivax candidate vaccine antigens. Vaccine, v. 17, n. 23-24, p. 3136-3144, 1999.

RODRIGUES, E. G.; TRAVASSOS, L. R. Nature of the reactive epitopes in Paracoccidioides brasiliensis polysaccharide antigen. J. Med. Vet. Mycol., v. 32, p.77-81, 1994.

SAN-BLAS, F.; SAN-BLAS, G.; COVA, L. J. A morphological mutant of Paracoccidioides brasiliensis strain IVIC Pb9. Isolation and wall characterization. J. Gen. Microbiol., v. 93, p. 209-218, 1976.

SAN-BLAS, G.; SAN-BLAS, F. Paracoccidioides brasiliensis: cell wall structure and virulence. A review. Mycopathologia, v. 62, p.77-86, 1977.

SAN-BLAS, G.; SAN-BLAS, F.; ORDAZ, D.; CENTENO, S.; ALBORNOZ, M. C. Chemical changes in cell wall structure of five strains of Paracoccidioides brasiliensis. Sabouraudia, v. 22, n. 3, p. 255-7,1984.

SAN-BLAS, G.; NIÑO-VEGA, G.; ITURRIAGA, T. Paracoccidioides brasiliensis and paracoccidioidomycosis: molecular approaches to morphogenesis, diagnosis, epidemiology, taxonomy and genetics. Med. Mycol, v. 40, n. 3, p. 225-242, 2002.

SANCHEZ, G. I.; SEDEGAH, M.; ROGERS, W. O.; JONES, T. R.; SACCI, J.; WITNEY, A.; CARUCCI, D. J.; KUMAR, N.; HOFFMAN, S. Immunogeneticy and protective efficacy of a Plasmodium yoelii HSP60 DNA vaccine in BALB/c mice. Infect. Immun., v. 69, n. 6, p. 3897-3905, 2001.

SARAIVA, E. C. O.; ALTEMANI, A.; FRANCO, M. F.; UNTERKIRCHER, C. S.; and CAMARGO, Z. P. Paracoccidioides brasiliensis-gp43 used paracoccidioidin. J. Méd. Vet. Mycol., v. 34, p. 155-161, 1996.

SCHECKELHOFF, M. A; DEEPE, G. D. JR. A deficiency in gamma interferon or interlekin-10 modulates T-Cell-dependent response to heat shock protein 60 from Histoplasma capsulatum. Infect. Immun., v. 73, p. 2129-2134, 2005. 
SCHOEL, B.; KAUFMANN, S. H. E. The unique role of heat shock protein in infections. In: EDEN, W; YOUNG, D.B. (Ed.). Stress proteins medicine. New York: Marcel Dekker, 1996. p. 27-53.

SEMIGHINI, C. P.; CAMARGO, Z. P.; PUCCIA, R.; GOLDMAN, M. H. S.; GOLDMAN, G. H. Molecular identification of Paracoccidioides brasiliensis by $5^{\prime}$ nuclease assay. Diagn. Microbiol. Infect. Dis., v. 44, p. 383-386, 2002.

SHEDLOCK, J. D.; WEINER, D. B. DNA vaccination: antigen presentation and the induction of immunity. J. Leukoc. Biol., v. 68, p. 793-806, 2000.

SHIKANAI-YATSUDA, M. A.; TELLES FILHO, F. Q.; MENDES, R. P.; COLOMBO, A. L.; MORETTI, M. L.; e grupo de consultores do consenso em paracoccidioidomicose. Consenso em Paracoccidioidomicose. Rev. Soc. Bras. Med. Trop., v. 39, n. 3, p. 297-310, 2006.

SHINNICK, T. M. Heat shock proteins as antigens of bacterial and parasitic pathogens. Curr. Top. Microbiol. Immunol., v. 167, p. 145-160, 1991.

SILVA, S. P.; BORGES-WALMSLEY, M. I.; PEREIRA, I.S.; SOARES, C. M. A.; WALMSLEY, A. R.; SOARES FELIPE, M.S. Differencial expression of a HSP70 gene during transition from the mycelial to the infective yeast form of the human pathogenic fungus Paracoccidioides brasiliensis. Mol. Microbiol., v. 31, n. 4, p. 1039, 1999.

SILVA-VERGARA, M. L.; MARTINEZ, R.; CHADU, A.; MADEIRA, M.; FREITASSILVA, G.; LEITE MAFFEI, C. M. Isolation of a Paracoccidioides brasiliensis strain from the soil of a coffee plantation in Ibia, State of Minas Gerais, Brazil. Med. Mycol., v. 36, p. $37-42,1998$.

SILVA-VERGARA, M. L.; MARTINEZ, R.; CAMARGO, Z. P.; MALTA, M. H.; MAFFEI, C. M.; CHADU, J. B. Isolation of Paracoccidioides brasiliensis from armadillos (Dasypus novemcinctus) in an area where the fungus was recently isolated from soil. Med. Mycol., v. 38, p. 193-199, 2000.

SLINGLUFF, C. L.; PETRONI, JR., G. R.; YAMSHCHIKOV, G. V.; HIBBITTS, S.; GROSH, W. W.; CHIANESE-BULLOK, K. A.; BISSONETTE, E. A.; BARND, D. L.; DEACON, D. H.; PETTERSON, J. W.; PAREKH, J.; NEESE, P. Y.; WOODSON, E. M.; WIERNASZ, C. J.; and MERRIL, P. Immunologic and clinical outcomes of vaccination with a multiepitope melanoma peptide vaccine plus low-dose interleukin2 administered either conncurrently or on a delayed schudele. J. Clin. Oncol., v.22, p.474-4485, 2004. 
SOARES, R. B. A.; GOMEZ, F. J.; SOARES, C. M. A.; DEEP, G. S. JR. Vaccination with Heat Shock Protein 60 induces a protective immune response against experimental Paracoccidioides brasiliensis pulmonary infection. Infect. Immun., v. 76, n. 9, p. 4214-4221, 2008.

SOUZA, A. R.; GESZTESI, J. L.; DEL NEGRO, G. M. B.; BENARD, G.; SATO, J.; SANTOS, M. V. B.; ABRAHÃO, T. B.; LOPES, J. D. Anti-idiotypic antibodies in patients with different clinical forms of paracoccidioidomycosis. Clin. Diagn. Labor. Immunol., v. 7, p.175-181, 2000.

SOUZA, M. C.; CORREAA, M.; ALMEIDA, S. R.; LOPES, J. D.; CAMARGO, Z.P. Immunostimulatory DNA from Paracoccidioides brasiliensis acts as T-Helper I promoter in susceptible mice. Scand. J. Immunol., v. 54, p. 348-356, 2001.

SOUZA, M. C.; GESZTESI, J. L.; SOUZA, A. R.; MORAES, J. Z.; LOPES, J. D.; CAMARGO, Z.P. Differences in reactivity of paracoccidioidomycosis sera with gp43 isoforms. J. Med. Vet. Mycol., v. 35, p. 13-18, 1997.

STOVER, E. P.; SCHAR, G.; CLEMONS, K. V.; STEVENS, D. A.; FELDMAN, D. Estradiol-binding proteins from mycelial and yeast-form cultures of Paracoccidioides brasiliensis. Infect. Immun., v. 51, p. 199-203, 1986.

TABORDA, C. P.; JULIANO, M. A.; PUCCIA, R.; FRANCO, M.; TRAVASSOS, L. R. Mapping of the T-cell epitope in the major 43-Kilodalton glycoprotein of Paracoccidioides brasiliensis which induces a Th-1 response protective against fungal infection in BALB/c mice. Infect. immun., v. 66, n. 2, p. 786-793, 1998.

TEWARI, R. P.; SHARMA, D. K.; MATHUR, A. Significance of thymus derived lymphocytes in immunity elicited by immunization with ribosomes of live yeast cells. J. Infect. Dis., v.138, p.605-613, 1978.

THEODORO, R. C.; BOSCO, S. M. G.; ARAÚJO Jr, J. P. ; CANDEIAS, J. M. G.; MACORIS, S. A. G.; TRINCA, L. A.; BAGAGLI, E. Dimorphism thermal tolerance, virulence and heat shock protein 70 transcription in different isolates. Mycopathologia, v. 165, p. 355-365, 2008.

THEUS, S. A.; ANDREWS, R. P.; STEELE, P.; WALZER, P. D. Adoptive transfer of lymphocytes sensitized to the major surface glycoprotein of Pneumocysti carinii confers protection in the rat. J. Clin. Invest., v.95, p.2587-2593, 1995. 
TIGHE, H.; CORR, M.; ROMAN, M.; RAZ, E. Gene vaccination: plasmid DNA is more than just a blueprint. Immunol. Today, v. 19, n. 2, p. 89-97, 1998.

TORRES-GUERRERO, H.; EDMAN, J. C. Melanin-deficient mutants of Cryptococcus neoformans. J. Med. Vet. Mycol., v. 32, p. 303-13, 1994.

TOWBIN, H.; STAEHELIN, T.; GORDON, J. Electrophoretic transfer of proteins from polyacrylamide gels to nitrocellulose sheets: procedure and some applications. Proc. Natl. Acad. Sci. USA, v. 76, n. 9, p. 4350-43, 1979.

TRAVASSOS, L. R.; TABORDA, C. P.; COLOMBO, A. L. Treatment options for paracoccidioidomycosis and new strategies investigated. Expert. Rev. Anti Infect. Ther., v. 6, n. 2, p. 251-262, 2008.

TRAVASSOS, L. R.; TABORDA, C. P.; IWAI, L. K.; CUNHA-NETO, E. C.; PUCCIA, R. The gp43 from Paracoccidioides brasiliensis: A major diagnostic antigen and vaccine candidate. In: DOMER, J.E.; KOBAYASHI, G.S. (Ed.). The Mycota XVII, Human Fungal Pathogens. Berlin-Heidelberg: Springer-Verlag, 2004. p. 279-296.

VICENTINI, A. P.; GESZTESI, J-L.; FRANCO, M. F.; SOUZA, W.; MARAES, J. Z.; TRAVASSOS, L. R.; LOPES, J. D. Binding of Paracoccidioides brasiliensis to laminin throught surface glycoprotein gp43 leads to enhancement of fungal pathogenesis. Infect. Immun., v. 62, p. 1465-1469, 1994.

VILLA, L. A.; TOBON, A.; RESTREPO, A.; CALLE, D.; ROSERO, D. S.; GOMEZ, B. L. and RESTREPO, A. Central nervous system paracoccidioidomycosis. Report of a case successfully treated with itraconazol. Rev Inst Med Trop Sao Paulo, v. 42, n. 2, p. 231, 234, 2000.

WANG, Y.; AISEN, P.; CASADEVALL, A. Cryptococcus neoformans melanin and virulence: mechanism of action. Infect. Immun., v. 63, p. 3131-3136, 1995.

WANKE, B. Epidemiology and paracoccidioidomycosis infection. In: WANKE, B.; LONDERO, A. T.; FRANCO, M.; LACAZ, C. S.; RESTREPO-MORENO A.; DEL NEGRO, G. (Ed.). Paracoccidioidomycosis. Boca Raton : CRC Press, 1994. p. 2438.

WHEELER, M. H.; BELL, A. A. Melanins and their importance in pathogenic fungi. In: McGINNIS, M. R. (Ed.). Current topics in medical mycology., New York: SpringerVerlag, 1987, v. 2, p. 338-387. 
WLOCH, M. K.; SMITH, L. R.; BOUTSABOUALOY, S.; REYES, L.; HAN, C.; KEHLER, J., SMITH, H. D.; SELK, L.; NAKAMURA, R.; BROWN, J. M.; MARBURY, T.; WALD, A.; ROLLAND, A.; KASLOW, D.; EVANS, T.; BOECKH, M. Safety and immunogenicity of a bivalent cytomegalovirus DNA vaccine in healthy adult subjects. J. Infect. Dis., v. 197, p. 1634-1642, 2008.

WOLFF, J. A.; LUDTKE, J. J.; ACSADI, G.; WILLIAMS, P.; JANI, A. Long-term persistence of plasmid DNA and foreign gene expression in mouse muscle. Human Mol. Genet., v.1, p. 363-369, 1992.

YARZABAL, L. A.; ANDRIEU, S.; BOUT D.; NAQUIRA F. Isolation of a specific antigen with alkaline phosphatase activity from soluble extracts of Paracoccidioides brasiliensis. Sabouraudia, v. 14, p. 275-80, 1976.

YOUNG, R.A. Stress proteins and immunology. Annu. Rev. Immunol., v. 8, p. 401420, 1990.]

ZACHARIAS, D.; UEDA, A.; MOSCARDI-BACCHI, M.; FRANCO, M.; SAN-BLAS, G. A comparative histopathological, immunological and biochemical study of experimental intravenous paracoccidioidomycosis induced in mice by three Paracoccidioides brasiliensis isolates. J. Med. Vet. Mycol., v. 24, p. 445-54, 1986. 